\title{
Abstracts of the IV Neuro Interventional Radiology Master Course: beyond frontiers in Neuro- Interventional Radiology
} Luis López-Ibor, MD1

1 Director, Neurointerventional Radiology Hospital Universitario Clínico San Carlos, Madrid, Spain

Dr. Luis López-Ibor

”luislopezibor@gmail.com

\section{Abstract}

The theme of the fourth NeurolMC course is BEYOND FRONTIERS IN NEUROINTERVENTIONAL RADIOLOGY. Conferences will explore the latest techniques in neurointerventional approaches to vascular pathology of the central nervous system. To summarize, on the first day we will be discussing the latest advances in endovascular embolization of complex aneurisms, flow diverters, and endovascular device flow disruption. Some of these techniques will be compared with older techniques such as the parent vessel occlusion test. A special lecture on microsurgical management of complex vascular pathology of the central nervous system will close the morning session. In the afternoon, we will continue the discussion on aneurysms and one conference will focus on a current and controversial subject: extracranial venous pathology as a potential contributor to degeneration. On Saturday, we begin with two sessions on anatomy and angioanatomy of the central nervous system, followed by series of lectures on complex pathologies, such as arteriovenous malformations and dural arteriovenous fistulae. The last group of conferences will focus on stroke, with the experiences of centers in Boston and Jacksonville, and the results of the MR CLEAN trial in the Netherlands. 
Dear friends \& colleagues,

After much work and anticipation, it is with great enthusiasm that we have the pleasure of presenting the fourth edition of the NeurolMC meeting, to be held on the 15-16th January 2015 at San Carlos Hospital in the heart of the Complutense University of Madrid. Those who already know us and have come to our previous encounters know that our ultimate goal is excellence. At this time we continue striving for this goal with a meeting of the masters. We break protocol and approach teachers and students in a relaxed, comfortable, and familiar environment. In short, it is our privilege to be able to share this year's NeurolMC with the pioneers of the $X X I$ century in neurointerventional techniques. Experts from five different continents will come together to give master lectures and talks in a new format close to a family meeting. I promise to surprise you again.

The Organizing Committee wishes you a profitable NeurolMC meeting.

Dr. Luis López-Ibor on behalf of the Organizing Committee.

To see the comprehensive scientific program, as well as the complete recording of all conferences and discussions, you can access our website at www.neuroimc.com. Abstracts for some of the lectures are available through Neurology and Neuroscience.

You can find more information about NeurolMC at neuroimc.com 


\section{Extracranial venous pathology. A potential contributor to neurodegeneration}

\section{Paolo Zamboni, MD.}

Vascular Diseases Center, University of Ferrara, Italy

\section{Abstract}

It has recently been shown how cerebral venous outflow may contain quantitative abnormalities (15) and qualitative (6-9), especially in response to postural and respiratory physiological mechanisms that govern the cerebral venous return $(4,5,10)$. The morphological basis of the abnormalities in venous return are intraluminal defects such septa, membranes, and faulty valves in the veins of the internal jugular and azygos vein; compressions muscle; hypoplasia or agenesis. (6-9) Practically, any layer of the jugular wall clearly shows aspects of vascular pathology in this condition. The intimal layer exhibits loss of endothelial cells (11); in the media it was also identified a marker in type III collagen much more expressed in the walls of the jugular veins of patients compared to control (12). Finally, there are calcifications found in the adventitia (13). Very often these abnormalities are variously associated with each other in the same individual.

From haemodynamic point of view, the restricted venous outflow through the major jugular and azygous routes result in a longer circulation time and activation of collateral circulation. Collectively such vascular framework has been defined Chronic Cerebrospinal Venous Insufficiency, English acronym CCSVI $(1,9,14)$. The research was initially focused on the association of CCSVI with multiple sclerosis (MS), but other studies showed possible and interesting associations with Alzheimer's disease, Parkinson's,
Meniere's syndrome, as well as its presence in healthy individuals, especially in the elderly. (15-19). From the pathophysiological point of view were identified two interesting consequences of CCSVI in the brain.

1) The presence of a restricted flow of a jugular and collateralization dell'outflow brain facilitates the presence of a state of generalized hypoperfusion and common to the entire brain $(2,20,21)$. This data is also present in individuals with CCSVI not associated with MS and other neurodegenerative disorders (21). The consequences of chronic hypoperfusion in concomitance with the development of a neurodegenerative process is a relative decrease of the capacity to repair the tissue injury.

2) The presence of increased resistance to venous flow in output from the skull can limit the process of re-absorption of cerebrospinal fluid at the level of the superior sagittal sinus. The result is a net flow of CSF, measured by advanced MRI methods, significantly reduced. (22-26) The presence of extracranial venous disease with reduced CSF flow seems to affect several neurodegenerative paintings. For example in MS is associated with a higher lesion load, or to the progression of a clinically isolated syndrome to a definitive diagnosis of MS. (27) The number of lesions in Alzheimer's disease has recently been reported to be related to abnormalities extracranial venous flow and slowed CSF flow. 
The consequences on cerebral oxygenation and blood-brain barrier, as well as on the physiology of the circulation of cerebrospinal fluid extracranial venous disease, must become objects of research to assess the potential contribution of this neglected portion of the tree circulatory development of neurodegenerative processes. Interestingly, it has been recently shown how endovascular procedures on the extracranial veins may improve perfusion and CSF flow as well (25).

Another hypothesis to be tested is related to the contribution of the venous system to the accumulation of iron in the brain parenchyma characteristic of many neurodegenerative diseases. An increased transit time in relation to cerebral venous disease extracranial (20-21), could also favor the phenomena of diapedesis of red blood cells through the blood brain barrier, becoming contributors of iron and a high oxidative stress (28-33).

\section{References}

1. Zamboni P, Sisini F, Menegatti E, Taibi A, Malagoni AM, Morovic S, Gambaccini M. An ultrasound model to calculate the brain blood outflow through collateral vessels: a pilot study. BMC Neurol. 2013 Jul 11;13:81.

2. Feng W, Utriainen D, Trifan G, Elias S, Sethi S, Hewett J, Haacke EM. Characteristics of flow through the internal jugular veins at cervical C2/C3 and C5/C6 levels for multiple sclerosis patients using MR phase contrast imaging. Neurol Res. 2012 Oct;34(8):802-9.

3. Feng W, Utriainen D, Trifan G, Sethi S, Hubbard D, Haacke EM. Quantitative flow measurements in the internal jugular veins of multiple sclerosis patients using magnetic resonance imaging. Rev Recent Clin Trials. 2012 May;7(2):117-26.

4. Beggs C, Shepherd S, Zamboni P. Cerebral venous outflow resistance and interpretation of cervical plethysmography data with respect to the diagnosis of chronic cerebrospinal venous insufficiency. Phlebology. 2012 Oct 11. [Epub ahead of print]

5. Zamboni P, Menegatti E, Conforti P, Shepherd S, Tessari M, Beggs C. Assessment of cerebral venous return by a novel plethysmography method. J Vasc Surg. 2012 Sep;56(3):677-85.e1.

6. Zivadinov R, Karmon Y, Dolic K, Hagemeier J, Marr K, Valnarov V, Kennedy CL, Hojnacki D, Carl EM, Hopkins LN, Levy El,
Weinstock-Guttman B, Siddiqui AH. Multimodal noninvasive and invasive imaging of extracranial venous abnormalities indicative of CCSVI: Results of the PREMiSe pilot study. BMC Neurol. 2013 Oct 20;13:151.

7. Karmon Y, Zivadinov R, Weinstock-Guttman B, Marr K, Valnarov V, Dolic K, Kennedy CL, Hojnacki D, Carl EM, Hagemeier J, Hopkins LN, Levy El, Siddiqui AH. Comparison of intravascular ultrasound with conventional venography for detection of extracranial venous abnormalities indicative of chronic cerebrospinal venous insufficiency. J Vasc Interv Radiol. 2013 Oct;24(10):1487-98.e1

8. Gianesini S, Menegatti E, Mascoli F, Salvi F, Bastianello S, Zamboni P. The omohyoid muscle entrapment of the internal jugular vein. A still unclear pathogenetic mechanism. Phlebology. 2013 May 16. [Epub ahead of print]

9. Zamboni P, Galeotti R, Menegatti E, Malagoni AM, Tacconi G, Dall'Ara S, Bartolomei I, Salvi F. Chronic cerebrospinal venous insufficiency in patients with multiple sclerosis. J Neurol Neurosurg Psychiatry. 2009 Apr; 80(4):392-9.

10. Zamboni P, Menegatti E, Pomidori L, Morovic S, Taibi A, Malagoni AM, Cogo AL, Gambaccini M. Does thoracic pump influence the cerebral venous return? J Appl Physiol (1985). 2012 Mar;112(5):904-10. 1

11. Zamboni P, Tisato $V$, Menegatti $E$, Mascoli F, Gianesini S, Salvi F, Secchiero P. Ultrastructure of internal jugular vein defective valves. Phlebology. 2014 Jun 27. pii: 0268355514541980. [Epub ahead of print]

12. Pascolo L, Gianoncelli A, Rizzardi C, Tisato $V$, Salom $\sqrt{ } \subset \mathrm{M}$, Calligaro C, Salvi F, Paterson D, Zamboni P. Calcium microdepositions in jugular truncular venous malformations revealed by Synchrotron-based XRF imaging. Sci Rep. 2014 Oct 7;4:6540.

13. Coen M, Menegatti E, Salvi F, Mascoli F, Zamboni P, Gabbiani G, Bochaton-Piallat ML. Altered collagen expression in jugular veins in multiple sclerosis. Cardiovasc Pathol. 2013 Jan-Feb;22(1):33-8.

14. Zamboni P, Consorti G, Galeotti R, Gianesini S, Menegatti E, Tacconi G, Carinci F. Venous collateral circulation of the extracranial cerebrospinal outflow routes. Curr Neurovasc Res. 2009 Aug;6(3):204-12.

15. Chung CP, Beggs C, Wang PN, Bergsland N, Shepherd S, Cheng CY, Ramasamy DP, Dwyer MG, Hu HH, Zivadinov R. Jugular venous reflux and white matter abnormalities in Alzheimer's disease: a pilot study. J Alzheimers Dis. 2014 Jan 1;39(3):601-9.

16. Zivadinov $R$, Chung CP. Potential involvement of the extracranial venous system in central nervous system disorders and aging. BMC Med. 2013 Dec 17;11:260

17. Beggs $C$, Chung CP, Bergsland N, Wang PN, Shepherd S, Cheng CY, Dwyer MG, Hu HH, Zivadinov R. Jugular venous reflux and brain parenchyma volumes in elderly patients with mild cognitive impairment and Alzheimer's disease. BMC Neurol. 2013 Oct 31;13:157

18. Filipo R, Ciciarello F, Attanasio G, Mancini P, Covelli E, Agati L, Fedele F, Viccaro M. Chronic cerebrospinal venous insufficiency in 
patients with $\mathrm{M} \sqrt{ } \bigcirc \mathrm{Cni} \sqrt{ }{ }^{\circledR} \mathrm{re}$ 's disease. Eur Arch Otorhinolaryngol. 2013 Dec 7. [Epub ahead of print]

19. Lanzillo R, Mancini M, Liuzzi R, Di Donato O, Salvatore E, Maglio V, Vacca G, Amato L, D’Anna G, Brunetti A, Brescia Morra V. Chronic cerebrospinal venous insufficiency in multiple sclerosis: a highly prevalent age-dependent phenomenon. BMC Neurol. 2013 Feb 13;13:20.

20. Zamboni P, Menegatti E, Weinstock-Guttman B, Dwyer MG, Schirda CV, Malagoni AM, Hojnacki D, Kennedy C, Carl E, Bergsland N, Magnano C, Bartolomei I, Salvi F, Zivadinov R. Hypoperfusion of brain parenchyma is associated with the severity of chronic cerebrospinal venous insufficiency in patients with multiple sclerosis: a cross-sectional preliminary report. BMC Med. 2011 Mar 7;9:22

21. Garaci FG, Marziali $S$, Meschini A, Fornari M, Rossi $S$, Melis M, Fabiano S, Stefanini M, Simonetti G, Centonze D, Floris R. Brain hemodynamic changes associated with chronic cerebrospinal venous insufficiency are not specific to multiple sclerosis and do not increase its severity. Radiology. 2012 Oct;265(1):233-9.

22. Zamboni P, Menegatti E, Weinstock-Guttman B, Schirda C, Cox JL, Malagoni AM, Hojanacki D, Kennedy C, Carl E, Dwyer MG, Bergsland N, Galeotti R, Hussein S, Bartolomei I, Salvi F, Zivadinov $\mathrm{R}$. The severity of chronic cerebrospinal venous insufficiency in patients with multiple sclerosis is related to altered cerebrospinal fluid dynamics. Funct Neurol. 2009 Jul-Sep;24(3):133-8.
23. Zamboni P, Menegatti E, Weinstock-Guttman B, Schirda C, Cox JL, Malagoni AM, Hojnacki D, Kennedy C, Carl E, Dwyer MG, Bergsland N, Galeotti R, Hussein S, Bartolomei I, Salvi F, Ramanathan M, Zivadinov R. CSF dynamics and brain volume in multiple sclerosis are associated with extracranial venous flow anomalies: a pilot study. Int Angiol. 2010 Apr;29(2):140-8.

24. Zivadinov R, Schirda C, Dwyer MG, Haacke ME, WeinstockGuttman B, Menegatti E, Heininen-Brown M, Magnano C, Malagoni AM, Wack DS, Hojnacki D, Kennedy C, Carl E, Bergsland N, Hussein S, Poloni G, Bartolomei I, Salvi F, Zamboni P. Chronic cerebrospinal venous insufficiency and iron deposition on susceptibility-weighted imaging in patients with multiple sclerosis: a pilot case-control study. Int Angiol. 2010 Apr;29(2):158-75.

25. Zivadinov R, Magnano C, Galeotti R, Schirda C, Menegatti E, Weinstock-Guttman B, Marr K, Bartolomei I, Hagemeier J, Malagoni AM, Hojnacki D, Kennedy C, Carl E, Beggs C, Salvi F, Zamboni P. Changes of cine cerebrospinal fluid dynamics in patients with multiple sclerosis treated with percutaneous transluminal angioplasty: a case-control study. J Vasc Interv Radiol. 2013 Jun;24(6):829-38.

26. Beggs CB, Magnano C, Shepherd SJ, Marr K, Valnarov V, Hojnacki D, Bergsland N, Belov P, Grisafi S, Dwyer MG, Carl E, Weinstock-Guttman B, Zivadinov R. 


\title{
Cerebral arterial fenestrations: a common phenomenon in unexplained subarachnoid haemorrhage
}

\author{
Hudák $\mathrm{I}^{1}$, Lenzsér $\mathrm{G}^{1}$, Lunenkova $\mathrm{V}^{1}$, Dóczi $\mathrm{T}^{1,2}$
}

1 Department of Neurosurgery, and Radiology:

2 University of Pécs and MTA-PTE Clinical Neuroscience MR Research Group, Pécs, Hungary

\section{Abstract}

In a significant percentage of patients suffering from acute subarachnoid haemorrhage $(\mathrm{SAH})$, the source of the bleeding remains undiscovered (idiopathic subarachnoid haemorrhage ( ISAH)). Fenestrations of intracranial arteries are variants resulting from the incomplete fusion of vessels during development. Their clinical significance is unknown yet. Fenestrations, generally hidden on routine 2D DSA, are more easily visualized by means of 3DRA, as 3DRA permits the improved visualization of cerebral vessels from any desired angle. In a prospective consecutive series of 287 patients admitted with acute SAH or for the management of an incidental aneurysm from 2009 to 2012, we employed 3DRA to identify the bleeding source and to assess the frequency and location of any fenestrations of intracranial arteries. Since 2013 all other ISAH cases were investigated with this method as well.

Between 2009 and 2012, of the 174 patients presenting with SAH, 153 had an aneurysm, whereas in 21 (12.1\%) no source of bleeding was found. In 20 (95.2\%) of these 21 patients with ISAH, an arterial fenestration was detected. The incidence of arterial fenestrations in the 153 patients with aneurysmal SAH was only $22.9 \%$, the difference between the two groups being statistically strongly significant $(p<0 \cdot 01)$. The incidence of arterial fenestration in the 113 patients with an accidental aneurysm was $23 \cdot 9 \%$.

Since 2013 an other 16 cases of ISAH were admitted, and in all of them an arterial fenestration was found.

Most of the fenestrations are located in the region of the ACOA, followed by the BA in the ISAH patients, while most of the hematomas have a symmetric, perimesencephalic distribution. In some cases there is a close anatomical relationship between the hematoma and the fenestration.

The female to male ratio in the 153 patients with aneurysmal SAH was 2:8:1, while that of the 37 idiopathic SAH patients was 1:1,2, the difference being statistically significant $(p<0.05)$ and suggesting a bleeding source other than aneurysms.

Conclusions: Arterial fenestration was detected in more than $20 \%$ of ruptured cerebral aneurysms, in contrast with nearly $100 \%$ of patients with ISAH. As fenestration is a developmental defect, a structural wall weakness making the vessel prone to rupture, its incidence of nearly $100 \%$ is strongly suggestive of a close connection with idiopathic SAH. The presented data indicate that arterial fenestrations (generally overlooked) are likely candidates as the mysterious source of idiopathic SAH. 


\title{
Arterial Fenestrations: A Common Phenomenon in Unexplained Subarachnoid Haemorrhage
}

\author{
Hudák $\mathrm{I}^{1}$, Lenzsér $\mathrm{G}^{1}$, Lunenkova $\mathrm{V}^{1}$, Dóczi $\mathrm{T}^{1,2}$ \\ 1 Department of Neurosurgery, and Radiology. \\ 2 University of Pécs and MTA-PTE Clinical Neuroscience MR Research Group, Pécs, Hungary
}

\section{Introduction}

In a significant percentage of patients suffering from acute subarachnoid haemorrhage $(\mathrm{SAH})$, the source of the bleeding remains undiscovered (idiopathic subarachnoid haemorrhage (ISAH)). Fenestrations of intracranial arteries are variants resulting from the incomplete fusion of vessels during development. Their clinical significance is unknown yet.

Fenestrations, generally hidden on routine 2D DSA, are more easily visualized by means of $3 D$ rotational angiography (3DRA), as 3DRA permits the improved visualization of cerebral vessels from any desired angle (Figure 1).

\section{Aims and Methods}

Our aim was to assess the frequency and location of any fenestrations of intracranial arteries and to examine their potentional involvement in the development of ISAH.

In a prospective consecutive series of 287 patients admitted with acute SAH or for the management of an incidental aneurysm from 2009 to 2012, we employed 3DRA to identify the bleeding source and to assess the frequency and location of any fenestrations of intracranial arteries.

Since 2013 all other ISAH cases were investigated with this method as well.
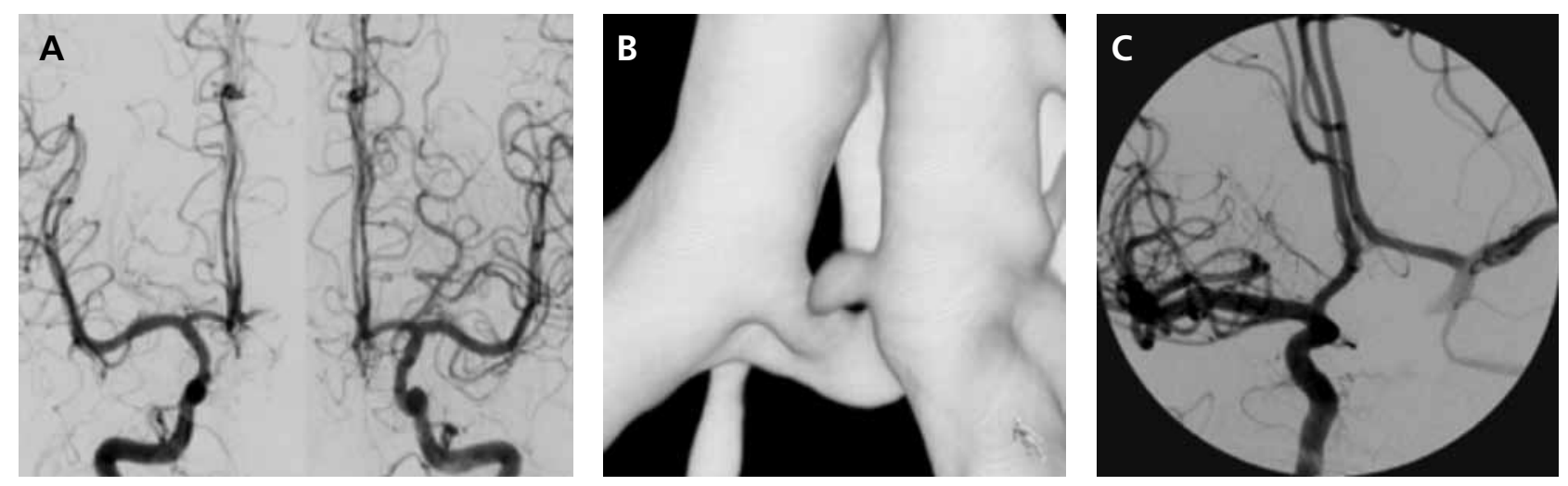

Figure 1. A. 2D carotid angiogramm in an ISAH patient in conventional AP view showing no abnormallity.

$B$. 3DRA of the ACoA region reveals the possible presence of fenestration of the ACoA.

C. 2D angiography in a non-conventional angle, perpendicular to the plane of the suspected fenestration confirms the presence of fenestrations of the ACoA. 


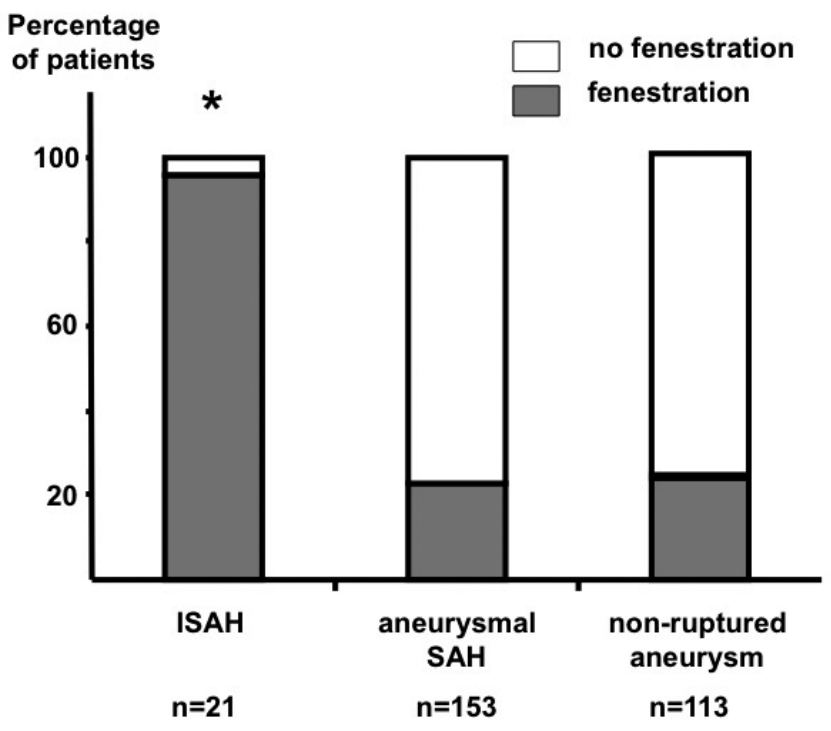

Figure 2. Proportion of patients with or without angiographically proven fenestrations.

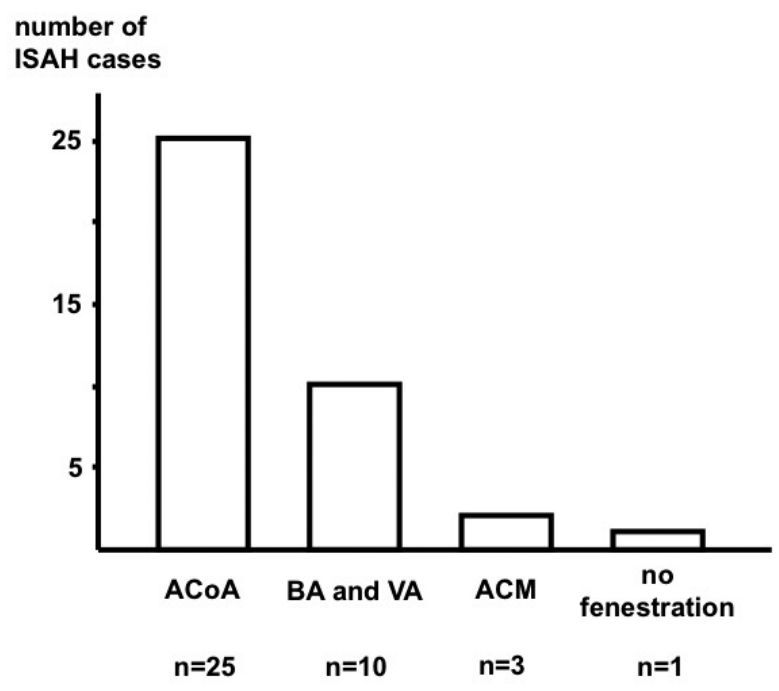

Figure 3. The location of arterial fenestrations in the ISAH patients.
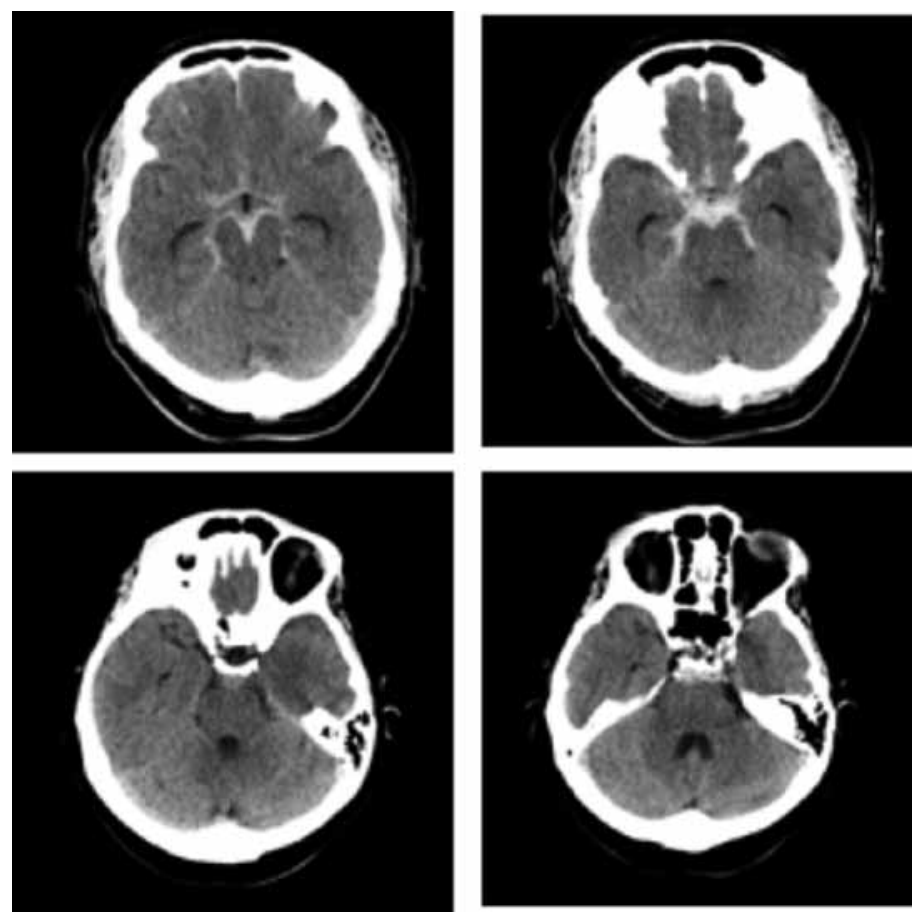

Figure 4. Perimesencephalic (upper row), and prepontin (lower row) distribution of SAH in two of our ISAH patients.

\section{Results}

Between 2009 and 2012, 174 patients was presented with SAH, 153 had an aneurysm, whereas in 21 (12.1\%) no source of bleeding was found (ISAH).

In 20 (95.2\%) of these 21 ISAH patients, an arterial fenestration was detected.

The incidence of arterial fenestrations in the 153 patients with aneurysmal SAH was 22.9\%, in the 113 patients with an accidental aneurysm it was $23.9 \%$.

The frequency of occurrence of fenestrations in the ISAH group was significantly higher than those in the other two groups $(p<0.01)$ (Figure 2).

Since 2013 an other 16 cases of ISAH were admitted, and in all of them an arterial fenestration was found. 

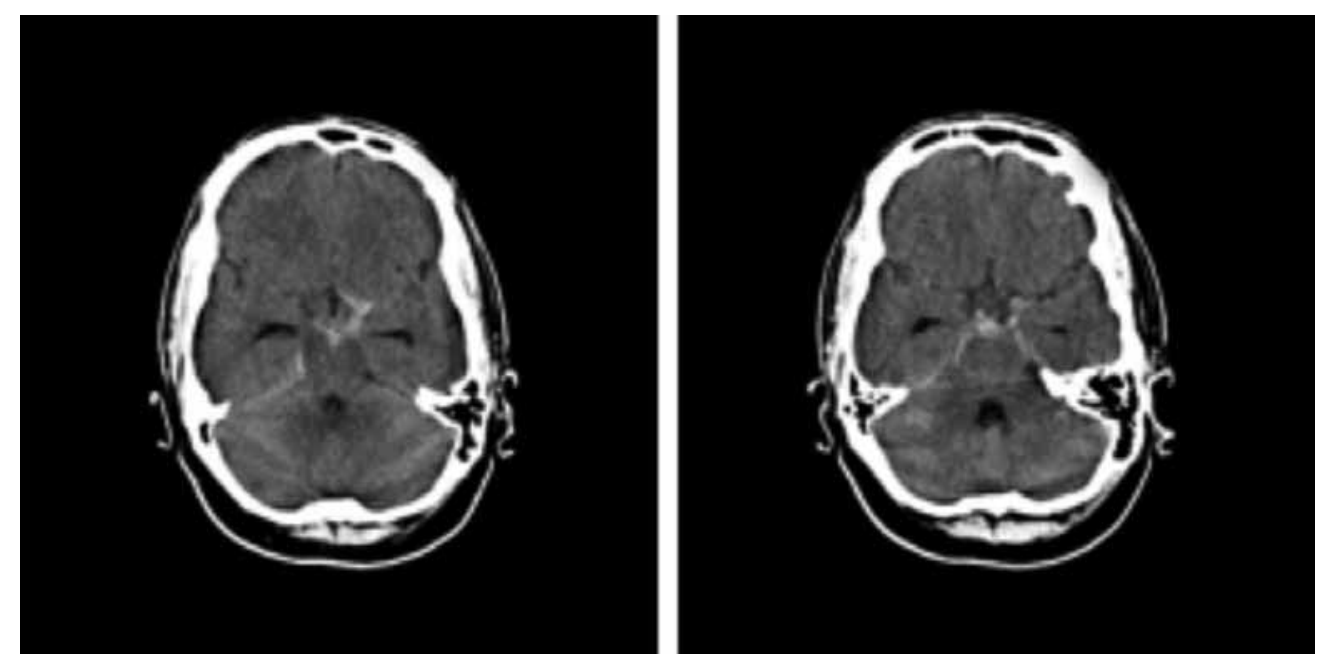

Figure 5. Perimesencephalic hemorrhage in an ISAH patient with a clot reaching the ACOA region, where an arterial fenestration was revealed.

In the ISAH cases the fenestration was found in the region of the $A C O A$ in 25 patients, on the basilar (BA) or vertebral artery (VA) in 10 patients and on the ACM in 3 patients (2 patients had fenestrations in two locations) (Figure 3).

The location of the hematoma was perimesencephalic-prepontin in 2/3 of our ISAH cases (Figure 4).

The mainly perimesencephalic-prepontin location of the hematoma seems to be contradictory to the mostly ACOA location of the fenestrations.

However, we speculate that the final location of the hematoma may be a result of flow and sedimentation in the cisternal spaces.

Furthermore, in some cases, there seems to be a direct connection between the hematoma and the site of the fenestration, supporting the potential role of the fenestration in the hemorrhage (Figures 5 y 6).

\section{Conclusion}

Arterial fenestration was detected in more than $20 \%$ of ruptured cerebral aneurysms, in contrast with nearly $100 \%$ of patients with ISAH. As fenestration is a developmental defect, a structural wall weakness making the vessel prone to rupture, its incidence of nearly $100 \%$ is strongly suggestive of a close connection with idiopathic SAH. The presented data indicate that arterial fenestrations (generally overlooked) are likely candidates as the mysterious source of idiopathic SAH. 


\section{Peripheral dissecting aneurysms: Anatomico-clinical considerations and endovascular management}

\section{Shakir Husain MD, DM}

Director, Neurointervention \& Stroke Program

Chairman, Department of Neurology

Institute of Neurosciences, SAKET CITY HOSPITAL, New Delhi. India
Peripherally situated aneurysms are often fusiform, and reach large or giant size in a substantial percentage of cases. The fusiform nature and large size of many peripheral intracranial aneurysms substantially complicate treatment paradigms. Direct surgical clipping or simple coil embolization of the aneurysm sac can't manage many of these lesions. Endovascular or surgical treatment consists of selective occlusion of the aneurysm or occlusion of the parent artery. Flow diverting intravascular devices constitutes a vessel preserving approach to some of the situations involving trunks of the medium size vessels.

Arterial trunk aneurysms unrelated to branching zones seem more likely to develop as a result of arterial dissection. Although some authors suggest atherosclerosis as the cause of fusiform aneurysm, others have demonstrated a lack of atherosclerosis in most surgical and pathologic studies. There are suggestions that fusiform aneurysms are lesions that start with internal elastic lamina (IEL) fragmentation due to hemodynamic stress followed by intimal hyperplasia, possibly as a reaction to the damage and successive dissection. Acute disruption of the IEL without intimal thickening has been observed in acute dissecting aneurysms. Other rare causes of peripheral aneurysm are septic embolism, drug abuse, haematological malignancies, Marfen syndrome, fibromuscular dysplasia etc.
Traditionally, most peripheral intracranial aneurysms managed endovascularly have been treated with parent artery occlusion. Various forms of balloon test occlusion (BTO) and amytal testing have been described to assess definitively the adequacy of collateral circulation. Although the BTO permits clinical evaluation and angiographic assessment of collateral circulation, its value before the parent arterial occlusion (PAO) is controversial. Therefore understanding the anatomical equivalence of collateral circulation and preservation of important perforators based on anatomical knowledge and understanding of possible embryological variations are of great help in avoiding morbidity of parent vessel sacrifice in the treatment of peripheral dissecting aneurysms.

In conclusion, peripheral cerebral aneurysms are very rare. They are mostly pseudo-aneurysm, commonly due of dissection. They are often seen in young individuals. Endovascular treatment is a preferred option for their treatment. Parent vessel occlusion is generally a safe and a short hospital stay option. Understanding of the anatomy of arterial territories and their perforators is crucial in making PAO safe. To say in the words of Pierre Lasjaunias "Learn the anatomy: it's the cheapest way of being safe" holds true in even in present time of technological advancement. 


\section{Case study (figure 1)}

30 years Female:

- Presenting complaints: sudden onset severe headache along with Vomiting.

- On Examination: Patient was fully conscious, GCS score of 15/15. Her pulse was 86/min; BP-140/80 $\mathrm{mm}$ of $\mathrm{Hg}$; there was no neck stiffness.
- Diagnosis: SAH H \& H Grade-l; peripheral dissecting P2 segment pseudo-aneurysm.

- Procedure: Balloon test occlusion (BTO) of left P1 followed by Endovascular Coiling of pseudoaneurysm with parent artery occlusion (PAO) under GA.

- Outcome: mRS-0

- CT Scan Head: Perimesencephalic subarachnoid haemorrhage

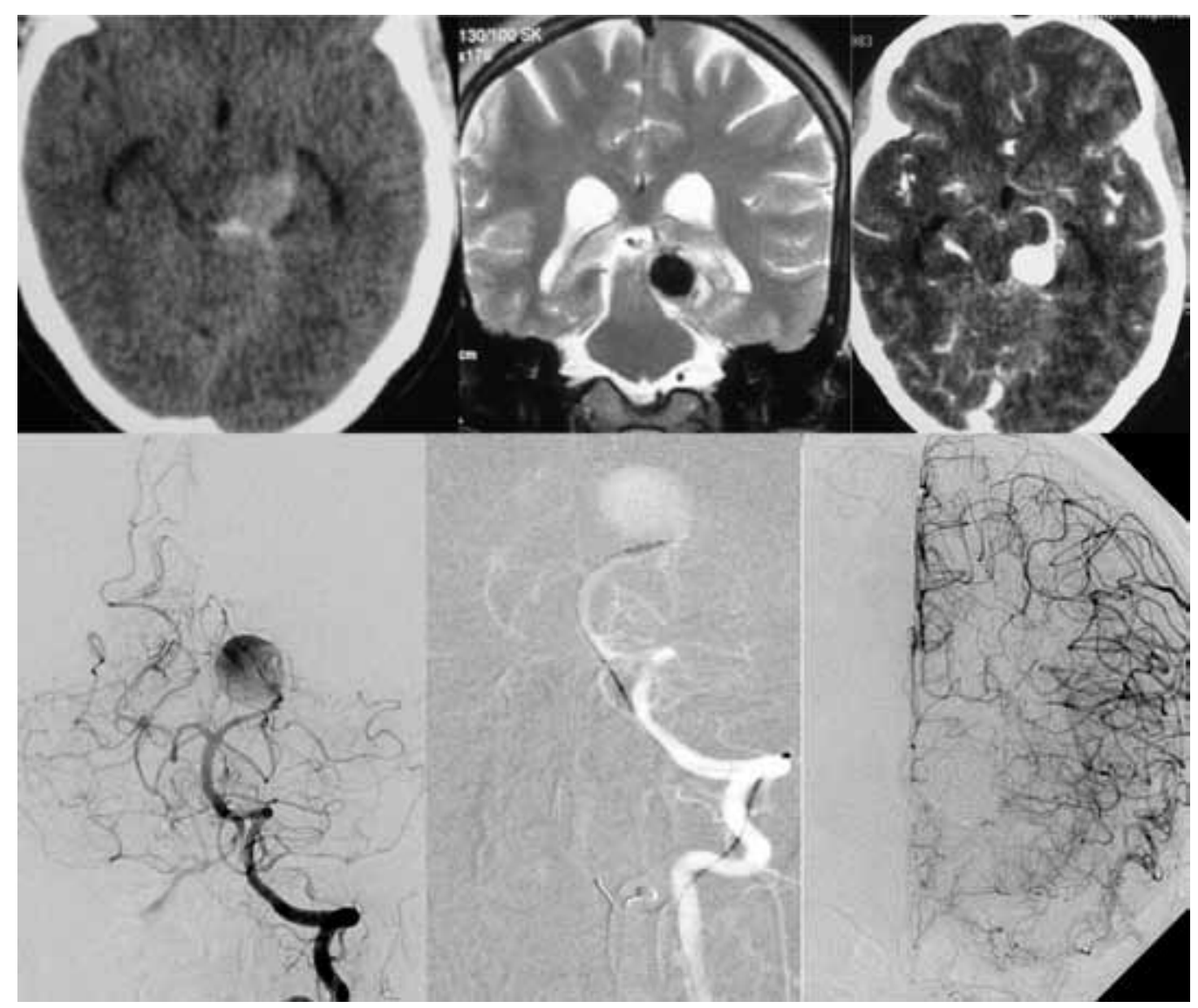

Figure 1. BTO of left P1 followed by Endovascular Coiling of pseudo-aneurysm with parent artery occlusion (PAO). (A) A CT scan head showing SAH; blood in perimesencephalic cistern. (B) MRI T2WI showing a large flow void in left perimesencephalic cistern. (C) CT angiography showing a pseudo-aneurysm of P2 segment of left PCA. (D) Left Vertebral artery DSA showing a pseudo-aneurysm of P2 segment of left PCA (E) Roadmap picture of left VA angiogram with an inflated microballoon in left P1 segment occluding PCA for BTO(F) Left ICA angiogram while left PCA -BTO was performed showing complete collateralization of the left PCA territory though MCA collaterals. (G) Unsubtracted picture of LVA angiogram showing coils in pseudoaneurysm occluding the P2 segment of PCA. Please note a small coil as a tail in the normal segment of left P2 important for the permanent occlusion of the PCA and avoidance of recurrence. (H) RVA - DSA showing complete occlusion of left PCA in P2 segment along with occlusion of pseudo-aneurysm. (I) final LICA angiogram in lateral view showing complete collateralization of the distal PCA territory through cortical anastomosis from MCA branches. 


\section{Targeted goal of partial embolization in AVMs using NBCA}

\section{Shakir Husain MD, DM}

Director, Neurointervention \& Stroke Program

Chairman, Department of Neurology

Institute of Neurosciences, SAKET CITY HOSPITAL, New Delhi. India
Brain arterio-venous malformations (AVMs) are one of the leading causes of intracerebral hemorrhage $(\mathrm{ICH})$ in young adults; However, $\mathrm{ICH}$ is the presenting symptom in only half of diagnosed brain AVM.

Brain AVMs can be treated by endovascular embolization to avoid future rupture. However, inspite of improvement in understanding of AVM angioarchitecture and concepts of embolization and development of flow guided catheters and various embolic agents the rate of complete obliteration of AVM remains low and poses a major challenge in the treatment of AVMs. The need for the intervention is determined by the risk of complications versus risk of conservative treatment.

Indication for the treatment of AVMs generally includes a) ruptured AVMs b) Unruptured symptomatic AVMs which affects the quality of life of an individual: Intractable Epilepsy, Intractable headache, progressive neurological deficit, raised ICT etc. therefore the goal of endovascular treatment can be broadly classified into two groups:

\section{Primary Goal is to prevent new / recurrent haemorrhage}

2. Other Goals May be:
a) To improve / stabilize neurological deficit
b) To treat intractable epilepsy
c) To reduce severity and frequency of headaches

Based in this concept the Objectives of embolization can be determined beforehand based on the clinical situation, angioarchitecture of AVM and desired clinical results:

1. Embolization for definitive cure

2. Embolization as a precursor for definitive operative resection

3. Embolization as a precursor for radiosurgery

4. Embolization as palliative treatment for progressive debilitating symptoms

5. Target embolization of high risk lesions - Post Radiosurgery and Post-Surgical

To achieve the desired goal of embolization a precise angiographic analysis of the vascular composition and intrinsic angioarchitecture of the nidus of the arteriovenous malformation by super-selective microcatheterisation to identify: types of feeding arteries and patterns of their supply, the number and vascular connections of nidal compartments, the types of arteriovenous shunts, the morphology of the vascular spaces composing the nidus and the number and exit patterns of draining veins must be studied before embarking on the use of embolic agents.

In conclusion, Brain AVM remains a complex clinical situation which requires appropriate case selection to keep the risk of Intervention low. Definition of goals and identification of targets prior to procedure is of paramount importance in achieving good results of treatment in clinical sense, therefore, an ideal picture result on angiography is not always a requirement in the Treatment of brain AVM. 


\section{Case Study (figure 1)}

Young man presenting with intraventricular haemorrhage due to rupture of right basal ganglion AVM with compact nidus.

- Procedure: Endovascular Embolization of AVM with NBCA.

- Outcome: mRS - 0

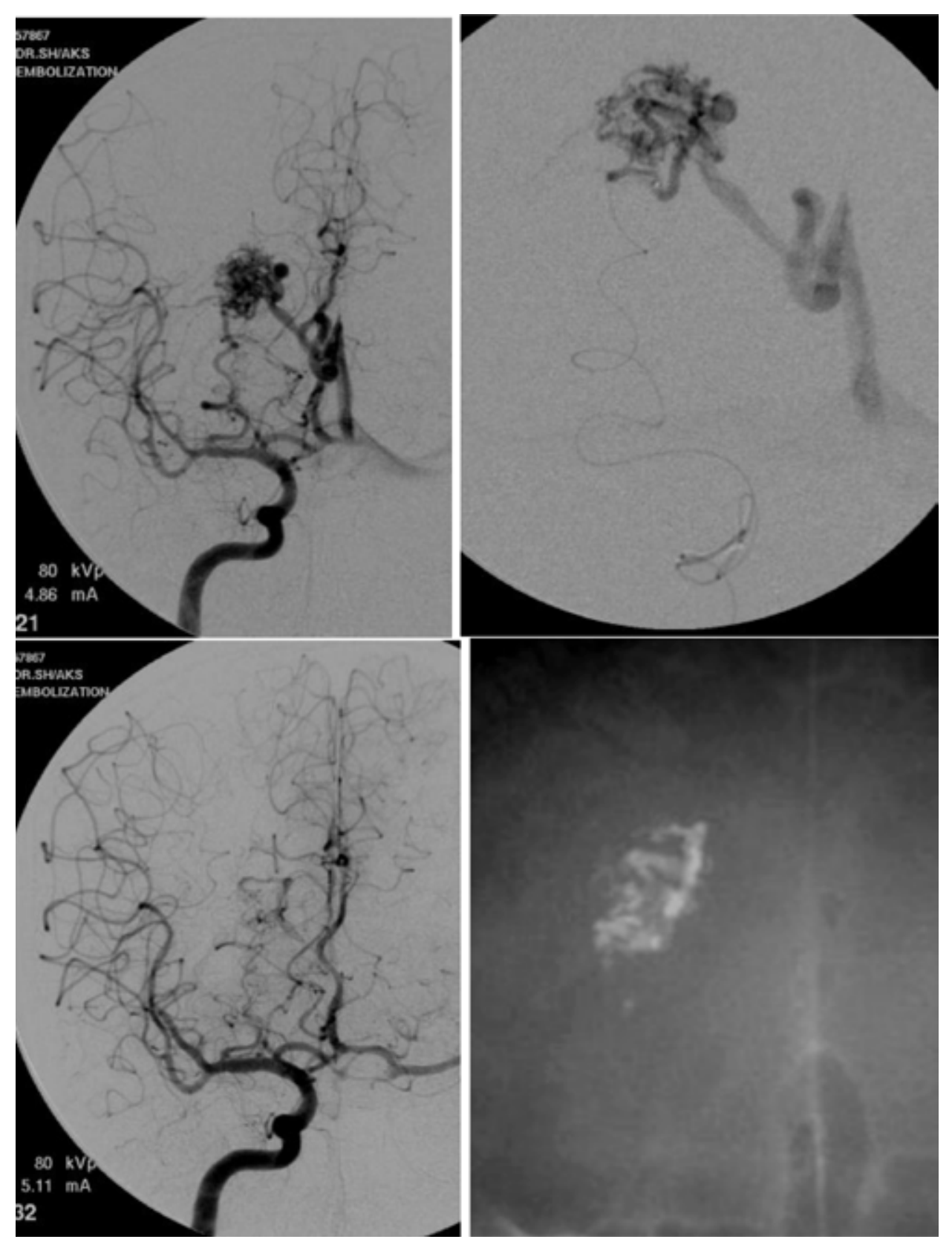

Figure 1. Endovascular embolization of AVM with NBCA. (A) Right ICA angiogram showing a small basal ganglion AVM, monopedicular type supplied from a lenticulostriate artery which appears dilated. The nidus appears compact and drains into the deep venous system through a dilated caudate vein and internal cerebral vein to Galenic system. (B) Microcatheterization of the nidus with the tip of microcatheter having intranidal position. (C) RICA angiogram showing a complete elimination of the AVM after embolization and (D) unsubtracted picture of skull showing cast of NBCA in the AVM nidus. 


\title{
Embolization of anterior, middle and basilar (fusiform and serpiginous) complex aneurysms: feasibility occlusion of parent vessel?
}

\author{
Luis Lopez-Ibor M.D. ${ }^{1}$, Juan Raul Brin M.D. ${ }^{1}$, Santiago Rosati M.D. ${ }^{1}$, Manuel \\ Moreu M.D. ${ }^{1}$, Sergio Vargas M.D. ${ }^{2}$, Gustavo Gómez-Bustamante M.D. ${ }^{3}$.
}

1 Department of Neurointerventional Radiology, Hospital Clínico San Carlos, Madrid, Spain.

2 Department of Neurointerventional Radiology, Hospital San Vicente de Paul, Medellín, Colombia.

3 Department of Neurosurgery, Hospital Clínico San Carlos, Madrid, Spain.

\section{Abstract}

Treatment of fusiform and serpiginous aneurysms of the circle of Willis represents a complex challenge. With the introduction of new devices and materials, such as flow diverters, some of these aneurysms can be treated successfully. However, flow diverters do not always result in aneurysm exclusion, and both periprocedural and delayed complications are well known. In serpiginous or fusiform aneurysms, irregular and dysplastic aneurysm walls often cause failure of stent adaptation and can result in endoleak. Also, some fusiform aneurysms can have heterogeneous wall morphology, with different diameters and points of stenosis, which impede correct flow-diverter stent apposition to the vessel wall and makes them unsuitable for stenting due to a high risk of intraluminal thrombosis. Test occlusion with coils and parent vessel occlusion allows for the analysis of clinical tolerance and collateral circulation. With this technique, complete aneurysm cure can be achieved with mass effect relief. This can be performed after acute hemorrhage since no antiaggregation is strictly necessary.

Methods: We describe our results in a series of 10 patients with aneurysms not suitable for balloon test occlusion, remodeling or stenting. Four were located in the anterior circulation (2 fusiform aneurysms, 2 serpiginous aneurysms) and 6 on the posterior circulation (2 dissecting aneurysms, 1 serpiginous AICA, 1 giant blister-like SCA, 2 basilar aneurysms). 
Discussion: Some authors have previously described the technique of parent vessel coil occlusion. To date, there are 11 series with 2-15 patients where the technique has been successfully employed. Sacrifice of P2 appears to be safe, and the basilar artery can be occluded if both posterior communicating arteries are larger than 1 $\mathrm{mm}$. If tolerated, balloon test occlusion ensures a low complication rate, with most series describing transient dysfunctions although permanent hemianopia and hemiparesis have been described.

Conclusions: In patients with fusiform, dissecting or serpiginous aneurysms which cannot be treated with remodeling, stenting, and coils, parent vessel occlusion after coil occlusion test while visualizing collateral circulation and clinical response is effective and safe with a low morbidity and mortality.

Keywords: parent vessel occlusion, aneurysms, giant aneurysms, fusiform aneurysms, serpiginous aneurysms

\section{Introduction}

Treatment of fusiform aneurysms continues to present a complex challenge. ${ }^{1}$ In recent years, the appearance of flow-diverter stents for the treatment of complex and large aneurysms has increased the feasibility of endovascular treatment for these aneurysms. ${ }^{2,3}$ However, many complications have been associated with the use of flow-diverting stents. ${ }^{3-5}$ Overall aneurysm closure in a recent metaanalysis is greater than $70 \%$, with a $10 \%$ risk of morbimortality. ${ }^{6}$ While acceptable in the setting of complex fusiform aneurysms, these risks are not negligible. Three complications associated with flow-diverter stents are particularly important. First, arterial stenosis and in-stent thrombosis and occlusion have been described. ${ }^{2}$ Delayed intraparenchymal hemorrhage is another rare but well-described complication that is not yet completely understood. Finally, the use of flow-diverter stents in fusiform aneurysms can sometimes lead to aneurysm nonocclusion in a manner similar to the endoleak phenomenon of aortic aneurisms, with perianeurysmal edema and worsening of mass effect. ${ }^{2,7}$ This is important because therapeutic management of this complication has not yet been standardized. Failure of the flow-diverter stent to adequately appose to the wall of the aneurysm because of irregular wall morphology, stenosis, and dilation, can increase the risk of these complications.

Parent artery occlusion, when preceded with an adequately performed occlusion test, is a safe and well-known procedure in the treatment of complex aneurysms. ${ }^{8}$ Several series have reported on the results of parent artery occlusion in the treatment of aneurysms in both the anterior and posterior cerebral circulation. ${ }^{8-19}$ The main advantage of parent artery occlusion, as opposed to flowdiverting stents, is its ability to be employed in ruptured aneurysms, since antiaggregation is 
not strictly necessary. The use of flow-diverters in the posterior circulation and in large or giant aneurysms is also associated with a significantly greater number of ischemic complications than if used on the anterior circulation, which is another limiting factor in the use of these devices. ${ }^{20}$ On the other hand, parent artery occlusion is usually well tolerated in the posterior circulation, and cases where it is not well tolerated can be reassigned a new treatment modality.

In this paper we describe our own series of patients treated by parent vessel occlusion.

\section{Methods}

Between 1996 and 2004, a total of 10 patients were sent to us for evaluation and were judged by our interventional neuroradiology staff and the senior author to have aneurysms not susceptible to treatment with balloon remodeling, stent placement, or balloon occlusion. Four patients had aneurysms located in the anterior circulation (2 fusiform aneurysms, 2 serpiginous aneurysms) and 6 on the posterior circulation (2 dissecting aneurysms, 1 serpiginous anteroinferior cerebellar artery (AICA), 1 giant blister-like superior cerebellar artery (SCA), 2 basilar aneurysms). All patients underwent preoperative cerebral computed tomography (CT) and magnetic resonance imaging (MRI).

All patients except one (the two year-old child) underwent cerebral angiography under local anesthesia and sedation. All patients received intravenous heparin anticoagulation at $80 \mathrm{lU} / \mathrm{Kg}$ body weight, up to a maximum of 5000 IU. All saline flushes were heparinized with $1000 \mathrm{IU}$ heparin. We performed double femoral artery catheterization in order to navigate two catheters simultaneously and test both direct vessel occlusion and indirect supply through collateral circulation.
Diagnostic angiography was initially performed at baseline mean arterial pressure, followed by new angiographic series and clinical correlation at lower mean arterial pressures between 50 and $70 \mathrm{mmHg}$. Following these series, we performed a coil occlusion test, which consisted of deploying one coil to occlude the parent vessel without coil liberation for a total time of 30 minutes. All patients underwent angiographical and clinical exploration while under the test occlusion. Repeat angiographic series were obtained to assess for collateral circulation supply to the occluded branch. Patients with aneurysms on the vertebrobasilar circulation underwent neurologic examination for lower cranial neuropathy and dysarthria/dysphonia. Patients with aneurysms on the anterior circulation underwent neurologic testing for aphasia, heminegligence, and motor functioning. In this series, no evoked potentials or electroencephalography were used. If coil occlusion was tolerated for 30 minutes without neurological deterioration from baseline, we proceeded with coil embolization of the parent vessel. After embolization, heparin was discontinued and patients without subarachnoid hemorrhage were antiaggregated with acetylsalicylic acid $100 \mathrm{mg}$ daily for one week.

\section{Results}

The coil occlusion test was successful in all 10 patients. No technical complications were encountered during the procedures. Coil embolization of the parent vessel was performed for all patients. We did not observe immediate postoperative ischemic or hemorrhagic complications and the procedure was well tolerated in all 10 patients. One transient worsening of the patient's neurological deficit was observed. At 10 years follow-up, no patient has experienced angiographic reopening of the aneurysm and all patients remain symptom-free. 


\section{Ilustrative cases}

\section{Case 1}

A 34 year-old man presented with progressive tetraparesis and brainstem dysfunction and was diagnosed of a partially thrombosed giant fusiform basilar artery aneurysm with significant mass effect on the pons (figure 1). He underwent an initial embolization attempt in September 1997, when we placed 27 coils into the basilar artery but did not completely occlude it. After this initial treatment, his symptoms worsened and we scheduled him for a second embolization procedure, which was performed on February 1998. In this occasion, after a successful coil occlusion test, the basilar artery was coiled on its middle third, closing the aneurysm (figure 2). His tetraparesis improved and the brainstem dysfunction greatly improved. At last follow-up he was able to walk with assistance, had no lower cranial neuropathies, and remained clinically stable.

\section{Case 2}

A 24 year-old woman presented with acute subarachnoid hemorrhage (SAH) from a ruptured giant fusiform A1 aneurysm with a saccular (blister-like) component in September 1999. The A1 segment could be closed successfully (figure $\mathbf{3}$ ).

\section{Case 3}

A 2 year-old boy with a left A2 fusiform aneurysm presented with intraventricular hemorrhage in February 1997. In this case, coil embolization was performed under general anesthesia (figure 4). The A2 segment was occluded, and follow-up angiography at 3 months showed complete aneurysm occlusion and adequate collateral circulation to the ACA territory (figure 5).

\section{Case 4}

A 56 year-old woman presented with a clinical history of left-sided visual disturbances, left ophthalmoparesis, and left-sided trigeminal dysfunction

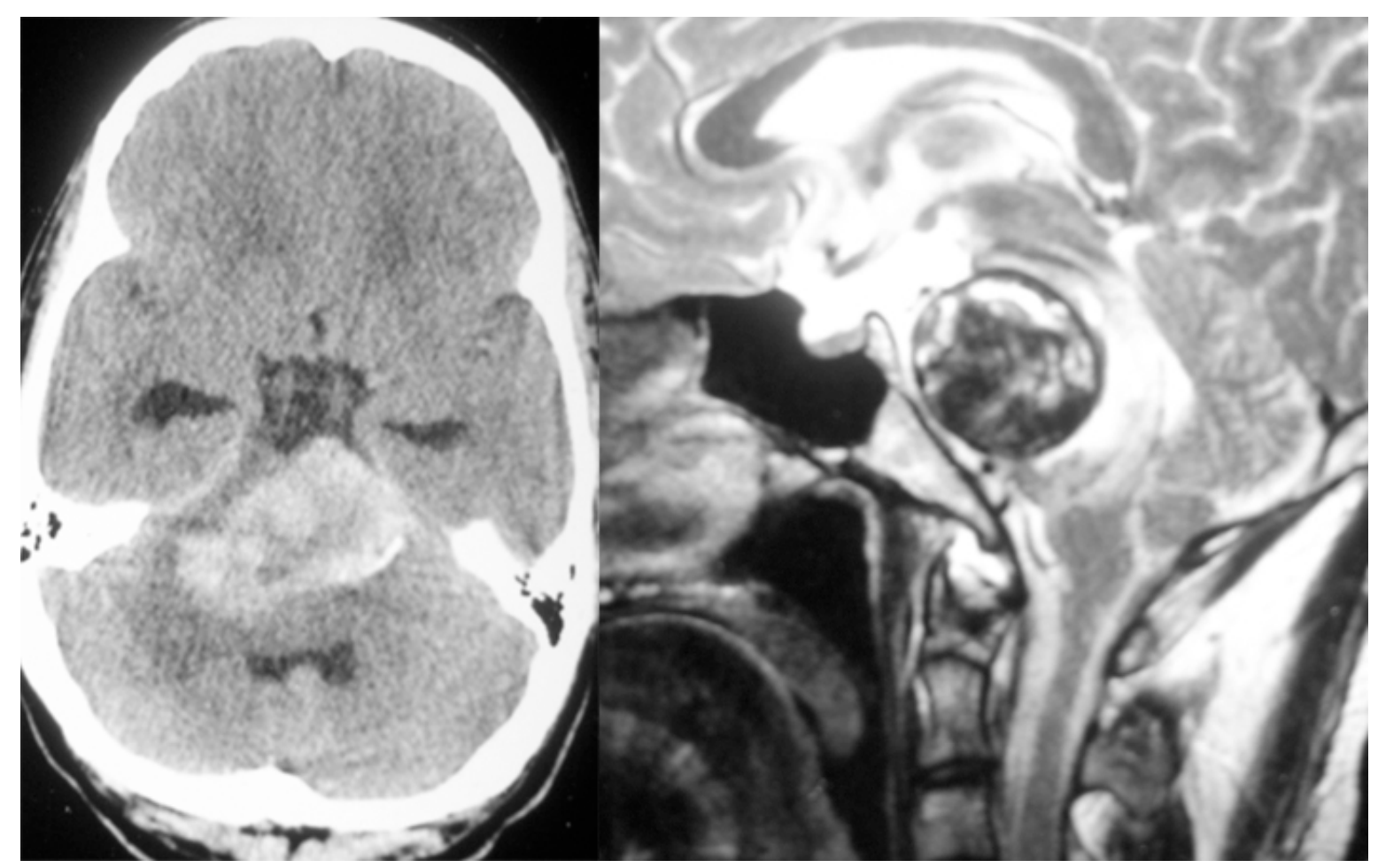

Figure 1. Case 1. Cerebral CT scan (left) and T2-weighted MRI (right) of a patient with a giant partially thrombosed fusiform aneurysm of the basilar artery. 


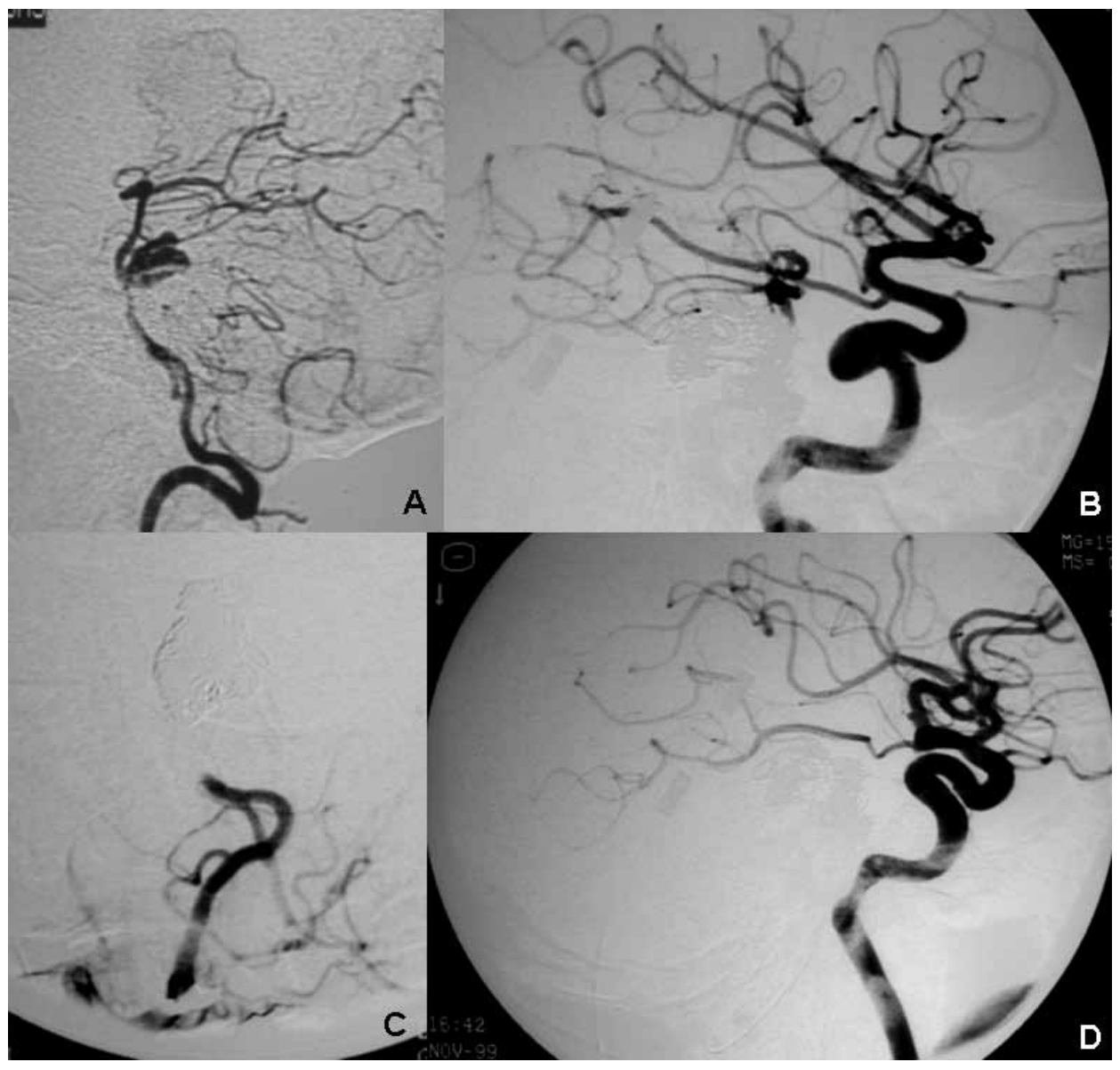

Figure 2. Case 1. A, lateral basilar angiography and B, lateral internal carotid angiography after initial coil embolization of the basilar artery. There is still some patency of the basilar artery and filling of the aneurysm. $C$, anteroposterior vertebral angiography and $D$, lateral internal carotid angiography after second embolization attempt which shows complete closure of the basilar artery and aneurysm exclusion with no aneurysm filling through the anterior circulation.
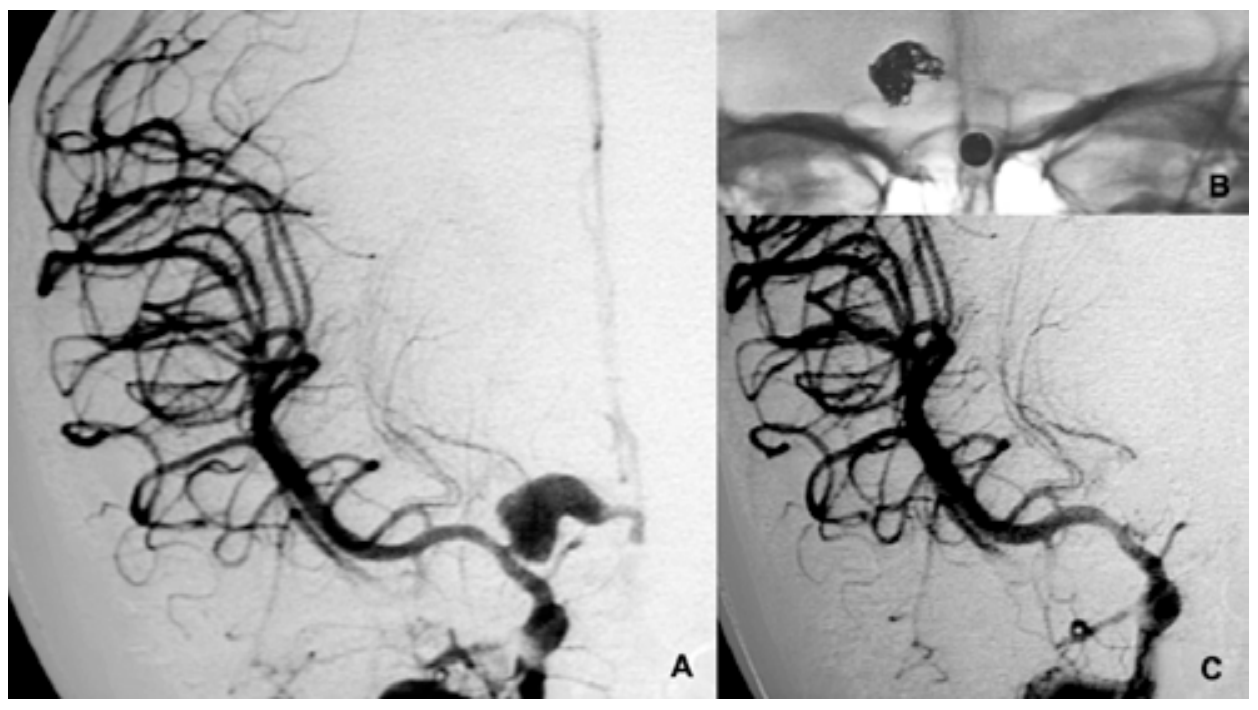

Figure 3. Case 2. A, anteroposterior digital substraction angiography that shows a large fusiform aneurysm on the right A1. B, Fluoroscopy after coil embolization of the aneurysm. $C$, angiography after coil embolization of the right $\mathrm{A} 1$. 


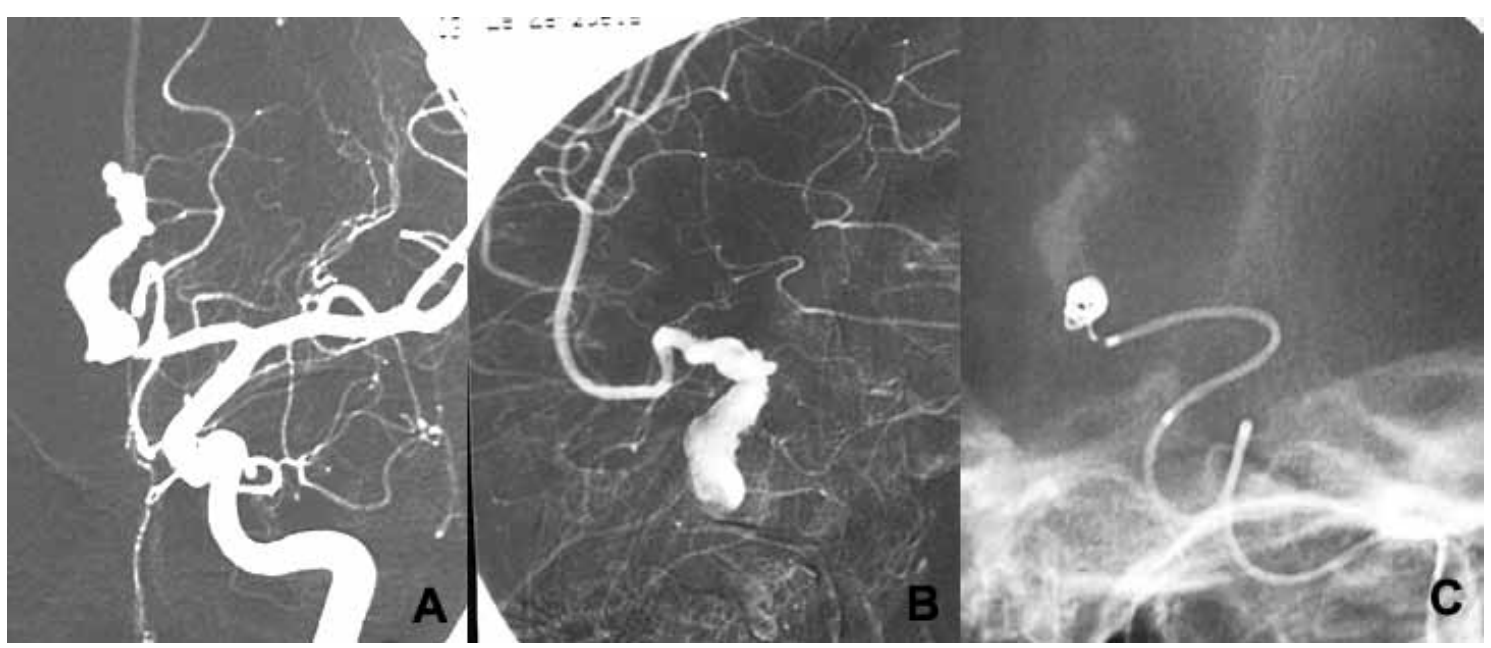

Figure 4. Case 3. A, anteroposterior, and B, lateral cerebral arteriography that shows a left $A 2$ fusiform aneurysm. $C$, coil occlusion of the parent vessel was performed.
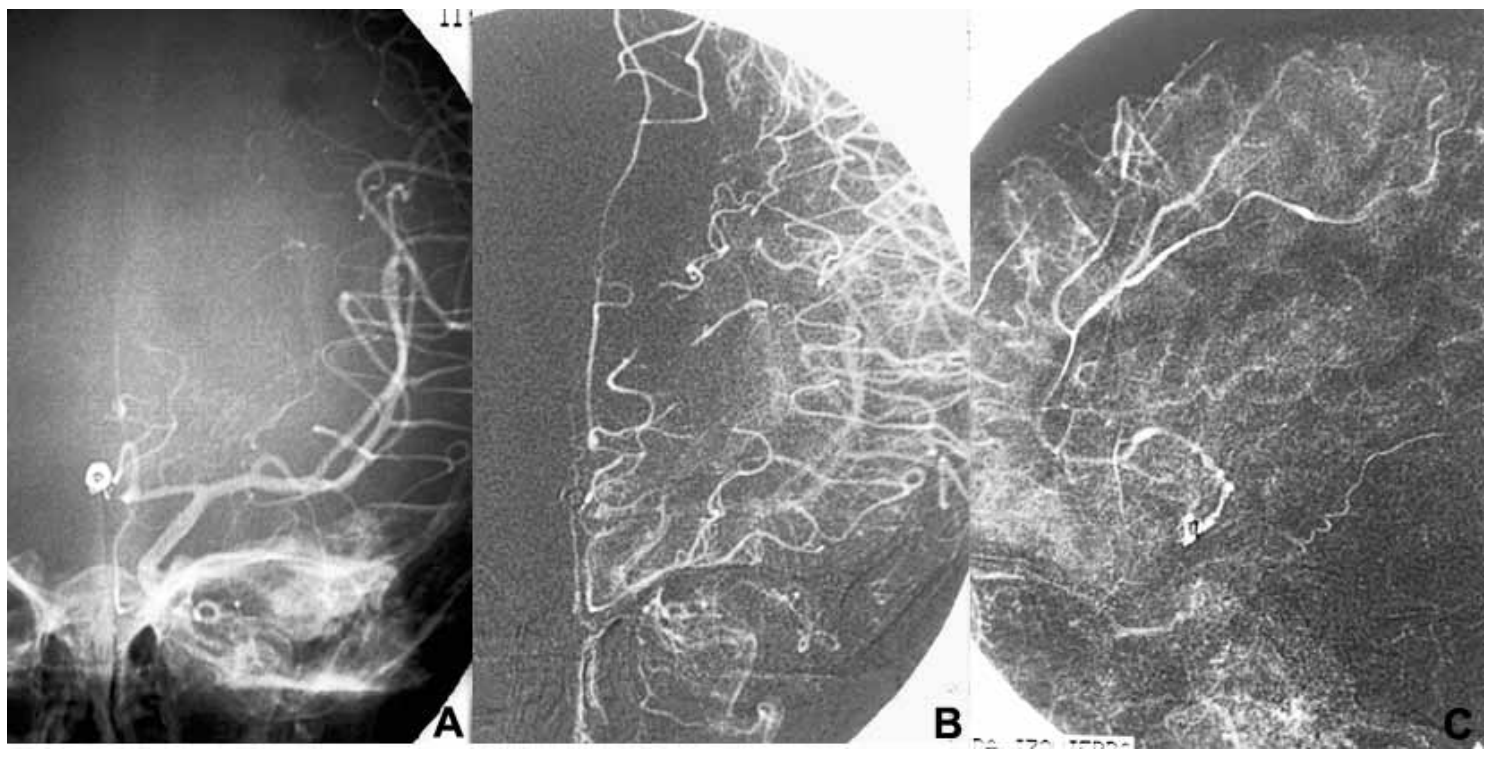

Figure 5. Case 3. Cerebral angiography at 3 months follow-up. A, anteroposterior early arterial phase which shows complete aneurysm occlusion. B and C, late arterial-early parenchymal phase which shows adequate perfusion through leptomeningeal collateral circulation of the ACA territory.

with facial anesthesia. She underwent cerebral angiography and was diagnosed with a giant left P1 aneurysm (figure 6). The P1 was occluded at its origin with good collateral circulation to the posterior cerebral artery (PCA) as shown in control angiographic series (figure 7).

\section{Case 5}

A 38 year-old patient with a serpiginous right M1 aneurysm who presented with seizures. Good tolerance in the occlusion test allowed for parent vessel occlusion and aneurysm cure (figure 8). The patient's seizures improved after treatment. 


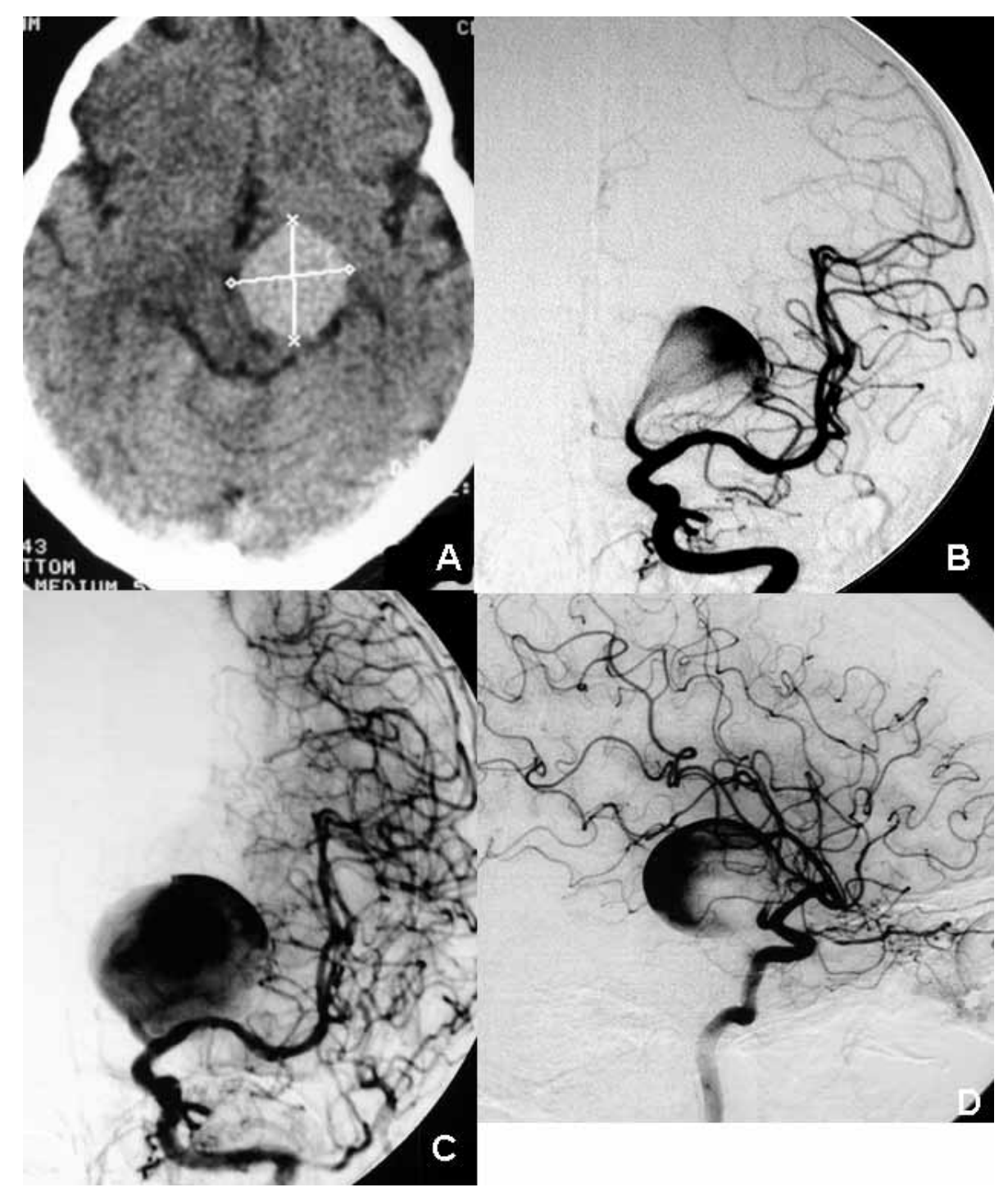

Figure 6. Case 4. A, cerebral CT scan which shows a partially thrombosed giant anterior communicating aneurysm with mass effect on the brainstem. $B$, anteroposterior DSA in early arterial phase and $C$, late arterial phase which shows the giant PComm aneurysm. $D$, lateral view of the angiography in arterial phase.

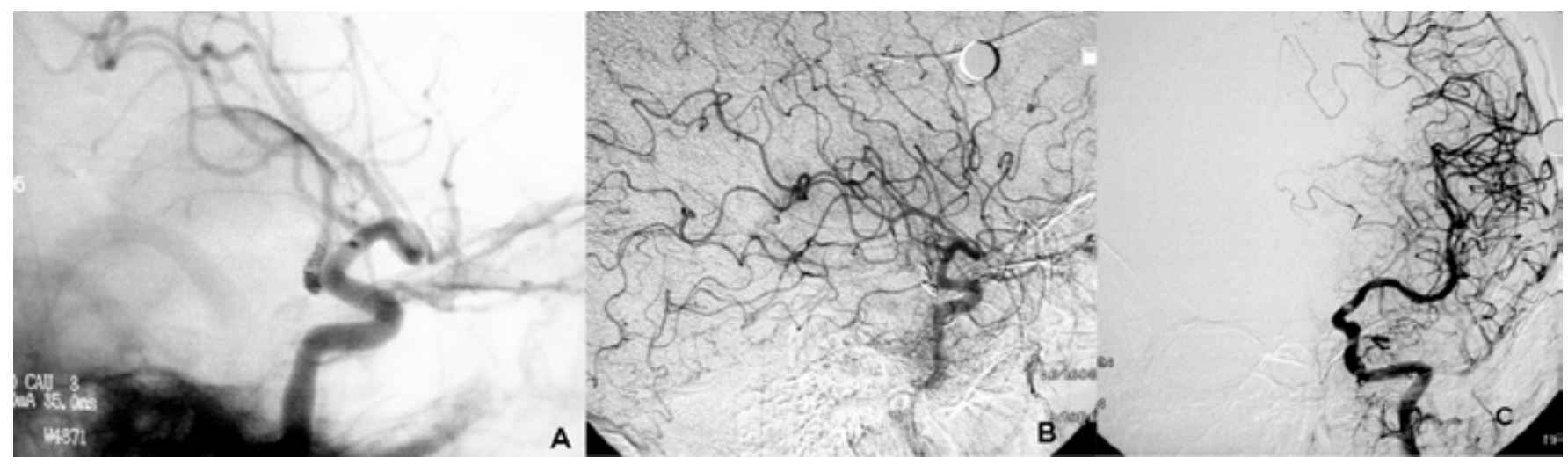

Figure 7. Case 4. A, cerebral angiography during coil embolization of the aneurysm neck. B and C, follow-up angiography at 3 months which shows complete exclusion of the aneurysm from the circulation, as well as adequate supply through collateral circulation of the posterior cerebral territory. 


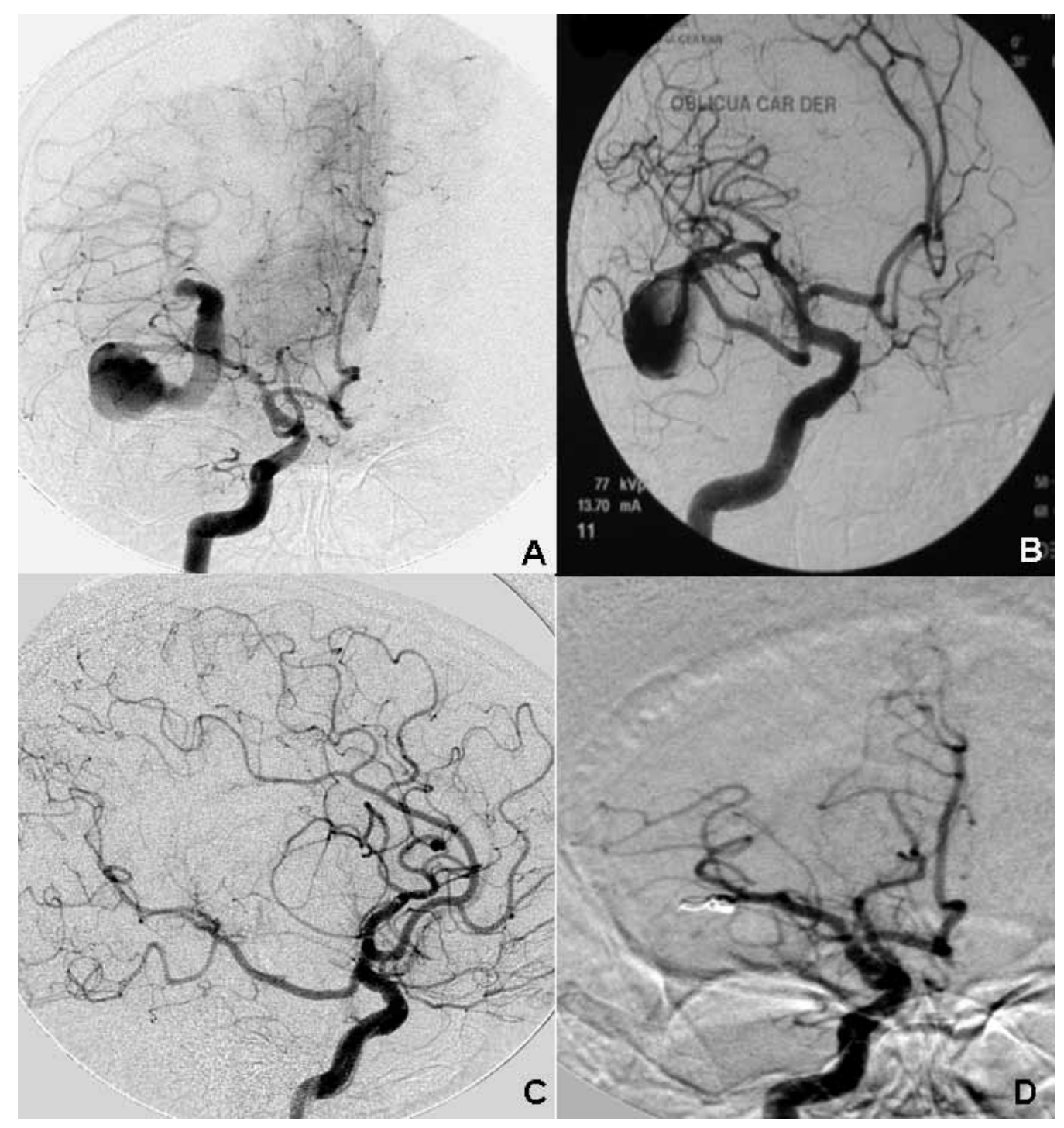

Figure 8. Case 5. A, anteroposterior, and B, lateral oblique DSA which shows a right-sided M2 serpiginous aneurysm. $C$ and $D$, post-treatment imaging show complete aneurysm exclusion after parent artery occlusion with coils.

\section{Discussion}

Parent artery occlusion in the treatment of fusiform aneurysms has been well described in the literature, both as an endovascular and open surgical procedure. Most series have shown endovascular parent vessel occlusion to be relatively well tolerated, with few severe neurological deficits after parent artery occlusion (Table 1). This is especially true for aneurysms of the posterior circulation. ${ }^{10,13,16}$
There is an extensive network of collateral circulation between branches of the PCA and the anterior circulation, in particular to the middle cerebral artery (MCA) from its temporal branches to temporal branches of the PCA, the anterior choroidal artery (to branches of the posterolateral choroidal arteries), and distal anterior cerebral artery (to branches of the splenial artery). ${ }^{10}$ In addition, collateral circulation also exists between branches of the SCA and PCA. For this reason, some researchers have 
Table 1. Treatment of fusiform aneurysms by parent artery occlusion published in the literature.

\begin{tabular}{|c|c|c|c|c|c|}
\hline Authors & $\begin{array}{l}\text { Journal of } \\
\text { publication }\end{array}$ & $\begin{array}{c}\text { Year of } \\
\text { publication }\end{array}$ & $\begin{array}{c}\text { Patient } \\
\text { population }\end{array}$ & Location & Complications \\
\hline Chaloupka et al. & AJNR & 1996 & 2 & SCA & cerebellar dysfunction \\
\hline Cloft et al. & AJNR & 1999 & 2 & $\begin{array}{l}1 \text { P4, } 1 \text { distal } \\
\text { AICA }\end{array}$ & none \\
\hline Eckard et al. & AJNR & 2000 & 9 & $\begin{array}{l}\text { Peripheral } \\
\text { aneurisms }\end{array}$ & $\begin{array}{c}1 \text { hypoacusia, } 1 \text { mild dysmetria, } 1 \text { visual field } \\
\text { cut and paresthesias }\end{array}$ \\
\hline Ciceri et al. & AJNR & 2001 & 7 & PCA & 1 hemianopsia and hemiparesis \\
\hline Hallacq et al. & AJNR & 2002 & 3 & P2 & none \\
\hline Arat et al. & Neuroradiology & 2002 & 8 & PCA & 1 hemianopsia \\
\hline Leibowitz et al. & AJNR & 2003 & 6 & VB & 1 recanalization and SAH \\
\hline Lubicz et al. & AJNR & 2003 & 3 & SCA & 1 facial palsy \\
\hline Biondi et al. & AJNR & 2006 & 8 & $\begin{array}{l}\text { Peripheral } \\
\text { aneurisms }\end{array}$ & $\begin{array}{l}1 \text { permanent hemianopsia, } 2 \text { transient } \\
\text { hemianopsias }\end{array}$ \\
\hline van Rooij et al. & AJNR & 2006 & 5 & PCA & 1 hemianopsia \\
\hline Andreou et al. & AJNR & 2007 & 15 & $\begin{array}{l}\text { Peripheral } \\
\text { aneurisms }\end{array}$ & 2 hemianopsias and 1 hemiparesis \\
\hline
\end{tabular}

Abb.: AICA, anteroinferior cerebellar artery; AJNR, American Journal of Neuroradiology; 4 , segment 4 of posterior cerebral artery; PCA, posterior cerebral artery; SAH, subarachnoid hemorrhage; SCA, superior cerebellar artery; VB, vertebrobasilar complex.

concluded that the sacrifice of P2 is safe. ${ }^{10,13,16,19}$ Collateral circulation to the territories supplied by perforators has not been as well studied. Relatively few reports exist of brainstem ischemia after parent vessel occlusion in the setting of a fusiform and/or partially thrombosed aneurysm. It would be reasonable to suspect that in this clinical setting, collateral circulation develops through other pathways.

One study by Steinberg discussed factors associated with good outcome after basilar artery occlusion. ${ }^{21}$ Since most of the collateral circulation after basilar artery occlusion comes from one or both posterior communicating (PComm) arteries, having both PComm arteries with a diameter greater than $1 \mathrm{~mm}$ was statistically associated with reduced risk of ischemic symptoms after basilar artery occlusion.

It is noteworthy that this study also reports a subpopulation of patients with preoperative brainstem mass effect symptoms that improved or resolved only with parent vessel occlusion. While this study refers to open surgery, the same results have been reported with endovascular techniques. ${ }^{19,22}$ Parent vessel occlusion seems to be a valid option for the treatment of aneurysms that present with mass effect or perianeurysmal edema, with successful rates of up to $87 \%$ improvement or resolution of symptoms. ${ }^{23}$ It should be noted, however, that these series are small and retrospective.

Some series have also described parent vessel oc- 
clusion in patients with distal aneurysms, where treatment with parent vessel preservation is not feasible.9,11 Proper balloon test occlusion or parent vessel occlusion is key in order to judge whether or not to proceed with coil occlusion, but if the test is well tolerated the procedure seems to have a low morbidity and acceptable risks. We prefer to perform the occlusion test with coils instead of balloon because it more closely resembles the hemodynamic characteristics that the post-treatment brain will manage. The use of intravenous heparin under this circumstance is mandatory in order to prevent ischemic complications.

Finally, a few words on open microsurgical parent vessel occlusion. Most studies that reported this technique are dated, with most of the new literature focusing on endovascular occlusion. In our opinion, we believe that performing an endovascular occlusion has the same benefits as open microsurgical occlusion, with the added benefits of being performed under local anesthesia without any added burden and sparing the patient a craniotomy and perivascular dissection. However, each case should be evaluated independently to select the best approach for each patient.

\section{Conclusions}

In patients with fusiform, dissecting or serpiginous aneurysms which cannot be treated with remodeling, stenting, and coils, parent vessel occlusion after coil occlusion test while visualizing collateral circulation and clinical response is effective and safe with a low morbidity and mortality.

\section{References}

1. Mizutani T, Miki Y, Kojima H, Suzuki H. Proposed classification of nonatherosclerotic cerebral fusiform and dissecting aneurysms. Neurosurgery. 1999;45: 253-260.
2. Lubicz B, Collignon L, Raphaeli G, et al. Flow-diverter stent for the endovascular treatment of intracranial aneurysms: A prospective study in 29 patients with 34 aneurysms. Stroke. 2010; 41: 2247-2253.

3. Alderazi YJ, Shastri D, Kass-Hout T, Prestigiacomo CJ, Gandhi CD. Flow diverters for intracranial aneurysms. Stroke Res Treat. 2014; 2014.

4. Clarençon F, Di Maria F, Biondi a., Chiras J, Sourour N a. Distant and delayed ( $>7$ Days) hemorrhage after treatment by flowdiverter stents in intracranial aneurysms: A rare but potentially serious complication. Am J Neuroradiol. 2013; 34: 81-82.

5. Fargen KM, Velat GJ, Lawson MF, Mocco J, Hoh BL. Review of reported complications associated with the pipeline embolization device. World Neurosurg. 2012; 77(3-4): 403-404.

6. Arrese I, Sarabia R, Pintado R, Delgado-Rodriguez M. Flowdiverter devices for intracranial aneurysms: Systematic review and meta-analysis. Neurosurgery. 2013; 73(2): 193-199.

7. Carneiro A, Rane N, Küker W, Cellerini M, Corkill R, Byrne J $\mathrm{V}$. Volume changes of extremely large and giant intracranial aneurysms after treatment with flow diverter stents. Neuroradiology. 2014; 56(1): 51-8.

8. Leibowitz R, Do HM, Marcellus ML, Chang SD, Steinberg GK, Marks MP. Parent vessel occlusion for vertebrobasilar fusiform and dissecting aneurysms. Am J Neuroradiol. 2003;24(May):902907.

9. Andreou a, loannidis I, Mitsos a. Endovascular treatment of peripheral intracranial aneurysms. AJNR Am J Neuroradiol. 2007; 28: 355-361.

10. Arat A, Islak C, Saatci I, Kocer N, Cekirge S. Endovascular parent artery occlusion in large-giant or fusiform distal posterior cerebral artery aneurysms. Neuroradiology. 2002; 44: 700-705.

11. Biondi A, Jean B, Vivas $E$, et al. Giant and large peripheral cerebral aneurysms: Etiopathologic considerations, endovascular treatment and long-term follow-up. Am J Neuroradiol. 2006; 27: 1685-1692.

12. Chaloupka JC, Putman CM, Awad I a. Endovascular therapeutic approach to peripheral aneurysms of the superior cerebellar artery. Am J Neuroradiol. 1996; 17: 1338-1342.

13. Ciceri EF, Klucznik RP, Grossman RG, Rose JE, Mawad ME. Aneurysms of the posterior cerebral artery: Classification and endovascular treatment. Am J Neuroradiol. 2001; 22 (January): 27-34.

14. Cloft HJ, Kallmes DF, Jensen ME, Lanzino G, Dion JE. Endovascular treatment of ruptured, peripheral cerebral aneurysms: Parent artery occlusion with short Guglielmi detachable coils. Am J Neuroradiol. 1999; 20(February): 308-310.

15. Eckard D a., O'Boynick PL, McPherson CM, et al. Coil occlusion of the parent artery for treatment of symptomatic peripheral intracranial aneurysms. Am J Neuroradiol. 2000; 21(January): 137-142.

16. Hallacq P, Piotin M, Moret J. Endovascular occlusion of the posterior cerebral artery for the treatment of P2 segment 
aneurysms: Retrospective review of a 10-year series. Am J Neuroradiol. 2002; 23(August): 1128-1136.

17. Lubicz B, Leclerc $X$, Gauvrit J-Y, Lejeune J-P, Pruvo J-P. Endovascular treatment of peripheral cerebellar artery aneurysms. AJNR Am J Neuroradiol. 2003; 24(July): 1208-13.

18. Tollard E, Niemtschik L, Darsaut TE, et al. Endovascular parent artery occlusion for the treatment of wide-neck A1 segment aneurysms: A single-center experience. Am J Neuroradiol. 2011; 32: $174-178$

19. Van Rooij WJ, Sluzewski M, Beute GN. Endovascular Treatment of Posterior Cerebral Artery Aneurysms. AJNR Am J Neuroradiol. 2006; 27: 300-305.

20. Brinjikji W, Murad MH, Lanzino G, Cloft HJ, Kallmes DF. Endovascular treatment of intracranial aneurysms with flow diverters: A meta-analysis. Stroke. 2013; 44: 442-447.
21. Steinberg GK, Drake CG, Peerless SJ. Deliberate basilar or vertebral artery occlusion in the treatment of intracranial aneurysms. Immediate results and long-term outcome in 201 patients. J Neurosurg. 1993; 79: 161-173.

22. Van Rooij WJ, Sluzewski M. Unruptured carotid artery aneurysms presenting with symptoms of mass effect: Outcome after selective coiling, parent vessel occlusion, and flow diversion. Am J Neuroradiol. 2013; 34(May): 940-941.

23. Hassan T, Hamimi A. Successful endovascular management of brain aneurysms presenting with mass effect and cranial nerve palsy. Neurosurg Rev. 2013; 36(1): 87-97; discussion 97. 


\section{Brainstem arteriovenous malformations: anatomical subtypes, assessment of "occlusion in situ" technique, and microsurgical results}

Han SJ, Englot DJ, Kim H, Lawton MT

\section{Abstract}

Object: The surgical management of brainstem arteriovenous malformations (AVMs) might benefit from the definition of anatomical subtypes and refinements of resection techniques. Many brainstem AVMs sit extrinsically on pia mater rather than intrinsically in the parenchyma, allowing treatment by occluding feeding arteries circumferentially, interrupting draining veins after arteriovenous shunting is eliminated, and leaving the obliterated nidus behind. The authors report here the largest series of brainstem AVMs to define 6 subtypes, assess this "occlusion in situ" technique, and analyze the microsurgical results.

Methods: Brainstem AVMs were categorized as 1 of 6 types: anterior midbrain, posterior midbrain, anterior pontine, lateral pontine, anterior medullary, and lateral medullary AVMs. Data from a prospectively maintained AVM registry were reviewed to evaluate multidisciplinary treatment results. RESULTS During a 15-year period, the authors treated 29 patients with brainstem AVMs located in the midbrain (1 anterior and 6 posterior), pons ( 6 anterior and 7 lateral), and medulla (1 anterior and 8 lateral). The nidus was pial in 26 cases and parenchymal in 3 cases. Twenty-three patients (79\%) presented with hemorrhage. Brainstem AVMs were either resected (18 patients, 62\%) or occluded in situ (11 patients, 38\%). All lateral pontine AVMs were resected, and the occlusion in situ rate was highest with anterior pontine AVMs (83\%). Angiography confirmed complete obliteration in 26 patients (89.6\%). The surgical mortality rate was $6.9 \%$, and the rate of permanent neurological deterioration was $13.8 \%$. At followup (mean 1.3 years), good outcomes (modified Rankin Scale [mRS] score $\leq 2$ ) were observed in 18 patients $(66.7 \%)$ and poor outcomes (mRS score of 3-5) were observed in 9 patients (33.3\%). The mRS scores in 21 patients (77.8\%) were unchanged or improved. The best outcomes were observed with lateral pontine (100\%) and lateral medullary (75\%) AVMs, and the rate of worsening/death was greatest with posterior midbrain and anterior pontine AVMs (50\% each).

Conclusions: Brainstem AVMs can be differentiated by their location in the brainstem (midbrain, pons, or medulla) and the surface on which they are based (anterior, posterior, or lateral). Anatomical subtypes can help the neurosurgeon determine how to advise patients, with lateral subtypes being a favorable surgical indication along with extrinsic pial location and hemorrhagic presentation. Most AVMs are dissected with the intention to resect them, and occlusion in situ is reserved for those AVMs that do not separate cleanly from the brainstem, that penetrate into the parenchyma, or are more anterior in location, where it is difficult to visualize and preserve perforating arteries (anterior 
pontine and lateral medullary AVMs). Although surgical morbidity is considerable, surgery results in a better obliteration rate than nonoperative management and is indicated in highly selected patients with high rerupture risks.

Keywords: AICA = anterior inferior cerebellar artery; $\mathrm{AVM}=$ arteriovenous malformation; $\mathrm{CM}=$ cavernous malformation; $C N=$ cranial nerve; PCA = posterior cerebral artery; PICA = posterior inferior cerebellar artery; SCA = superior cerebellar artery; SPS = superior petrosal sinus; VA = vertebral artery; VBJ = vertebrobasilar junction; arteriovenous malformations; brainstem; mRS = modified Rankin Scale; occlusion in situ; subtypes; surgery; vascular disorders 


\title{
Radiosurgery for cerebellar arteriovenous malformations: does infratentorial location affect outcome?
}

\author{
Ding D, Starke RM, Yen CP, Sheehan JP.
}

\section{Abstract}

Objective: The cerebellum is an uncommon location for arteriovenous malformations (AVM) with unique angioarchitecture compared to the cerebrum. We evaluate the outcomes of radiosurgery in a cohort of cerebellar AVMs and assess the effect of infratentorial location by comparing them to a matched cohort of supratentorial AVMs.

Methods: From a prospective AVM radiosurgery database of 1400 patients, we identified 60 cerebellar AVM patients with at least 2 years of radiologic follow-up or obliteration. The median volume and prescription dose were $2.3 \mathrm{~mL}$ and $22 \mathrm{~Gy}$, respectively. The median radiologic followup was 39 months. The cerebellar AVM patients were matched (3:1) to a cohort of supratentorial, lobar AVM patients based on AVM size and patient age. Univariate and multivariate Cox proportional hazards regression analyses were used to identify factors associated with obliteration and favorable outcome.
Results: Cerebellar and supratentorial AVMs were similar in baseline characteristics except for an increased incidence of ruptured lesions in the cerebellar AVM cohort $(P<.001)$. Obliteration was achieved in $72 \%$ of cerebellar AVMs. Younger age $(P=.019)$, no preradiosurgery embolization $(P<.001)$, and decreased volume $(P=.034)$ were independent predictors of obliteration. The annual risk of postradiosurgery hemorrhage in cerebellar AVMs was $1.3 \%$. The rates of symptomatic and permanent radiation-induced changes were $7 \%$ and $3 \%$, respectively. Compared with the matched supratentorial AVM cohort, there was no difference in the rates of obliteration, postradiosurgery hemorrhage, or symptomatic radiation-induced changes.

Conclusions: Radiosurgery is an effective treatment modality for cerebellar AVMs with relatively limited adverse events. Infratentorial location did not affect radiosurgery outcomes.

Keywords: Cerebellum; Gamma knife; Intracranial arteriovenous malformation; Radiosurgery; Stroke; Vascular malformations 


\section{Long-term control of large pontine arteriovenous malformation using gamma knife therapy: a review with illustrative case}

Mortazavi MM, Patel D, Griessenauer CJ, Tubbs RS, Fisher WS 3rd.

\section{Abstract}

Brain stem arteriovenous malformations (AVMs) are rare and their clinical management is controversial. A location in highly eloquent areas and a greater risk of radionecrosis are both serious issues for radiosurgery of this entity. We report a case of a pontine AVM treated successfully with gamma knife therapy. At 3 years angiographic follow-up, imaging demonstrated complete thrombosis and there were no new neurological deficits, and at 7 years clinical follow-up, the patient continued to be neurologically stable. Although all treatments carry risk of neurological compromise, gamma knife therapy may offer the best treatment option for brain stem AVMs as seen in the case presented herein. This case illustrates a rare case of holopontine AVM tolerating gamma radiation with complete angiographical response and minimal neurological sequalae.

Keywords: Arteriovenous malformation; brain stem 


\title{
Posterior fossa arterio-venous malformations: current multimodal treatment strategies and results
}

\author{
Stein KP, Wanke I, Schlamann M, Dammann P, Moldovan AS, Zhu Y, Sure U, \\ Sandalcioglu IE.
}

\section{Abstract}

The present study aimed to determine the clinical presentation, the multimodal interdisciplinary treatment strategies and outcome of posterior fossa arterio-venous malformations (AVMs) in our neurovascular centre. Fifty-three patients with a posterior fossa AVM were seen between 1998 and 2012 and analysed retrospectively. Patients were either managed conservatively or treated with endovascular, microsurgical or radiosurgical procedures or in combination. Thirty-nine patients (74\%) presented with intracranial haemorrhage and 14 patients (26\%) with unspecific symptoms. In 22 cases with haemorrhage (56\%), an intracerebellar haematoma was found, whereas 17 patients (44 $\%)$ suffered from subarachnoid haemorrhage. AVMs were located in the cerebellum in 44 patients $(83 \%)$, in the brainstem in four patients $(7.5 \%)$ and the cerebello-pontine angle in another four individuals (7.5\%). Forty-two patients (79 $\%)$ were treated either by emboliziation ( $n=12$, $29 \%$ ), surgical resection ( $n=16,38 \%$ ), surgical resection with preoperative embolization $(n=12$, $29 \%)$ or radiotherapy alone $(n=2,4 \%)$. A total of eleven patients did not receive any treatment (21\%). Both, morbidity and mortality related to treatment were $12 \%$, whereas overall morbidity and mortality was 26 and $15 \%$, respectively. Complete AVM elimination was achieved in 81 $\%$ of the treated lesions. A multimodal treatment sequence nowadays represents the gold standard for posterior fossa AVMs. Patients are at high risk for morbidity and mortality, due to the impact of haemorrhage and treatment. Therefore, treatment has to be thoroughly indicated, especially for those patients without bleeding. The initial neurological condition seems to be crucial in terms of clinical outcome. 


\section{The circle of willis: historical review and evolution of concepts}

\section{Nikolay Gabrovsky, MD, PhD}

Department of Neurosurgery, University Hospital Pirogov, Sofia, Bulgaria e-mail: gabrovsky@gmail.com

\section{Abstract}

In 1664, Thomas Willis - an English physician, scientist, pioneer in research andProfessor of Natural Philosophy at Oxford published "Cerebri Anatome: Cui Accessit Nervorum Descriptio et Usus" (Anatomy of the Brain, with a description of the Nerves andtheir Function). In his work, he made a thorough description, detailed illustration and suggestion about the physiologic significance of the arterial anastomoses in the base of the brain actually known as "the circle of Willis".

This scientific work was made in the dismal atmosphere of the end of the long-lasting and exhausting English Civil War (1642-1651) where the Royalists were fighting against Parliamentarians and after the recurrence of the plague known as the Second plague pandemic 1623-40, 1644-54 and the Great Plague of London (1665-66). But the most challenging obstacle was the ruling Galenic concept in medicine.

Following the concepts of Claudius Galenus (AD 129 - 200) that influenced Western medical science for more than 1,300 years, the arterial and the venous blood were part of two separate, oneway systems. It was told that the venous blood is generated in the liver and the arterial blood - in the heart, from where they were distributed in an ebband-flow motion. The first fundamental challenge of this concept was made by the Arab physician Ibn al-Nafis born in 1213 in Damascus who was the first to describe the pulmonary circulation. Later, Leonardo's anatomical drawings (1489-1515) and the fundamental work of Andreas Vesalius published in 1543 - De humani corporis fabrica (The Structure of the Human Body) gave new dimension of our anatomical knowledge. But one of the greatest breakthroughs in our understanding of the human body was made by the English physician William Harvey who in 1628 published a revolutionary concept describing the heart as a pump and postulating that the blood is pumped endlessly round a very precise circuit.

Before Willis, with different grade of precision and completeness, the anastomotic circle was also described in the scientific works of Gabriel Fallopius in 1561, Guilio Casserio (published in 1627 after his death), Johann Vesling in 1647, Johan Jacob Wepfer in 1658. But Thomas Willis was the first to describe the circle, to present the first realistic, high quality illustrations and to suggest the physiologic significance of the circle in maintaining collateral flow to the brain. 
In the beginning of the XX century, a completely new method for the study of the circle of Wills has become available with the development of the cerebral angiography by Egas Moniz.

Another perspective of the knowledge was given by the neuroembriological studies of Santiago Ramon y Cajal (1852-1934), of His and von Kupffer 192050 , of George Streeter but mainly by the works of Dorcas H. Padget published in 1945: "The development of the cranial arteries in the human embryo" and the "The circle of Willis: its embryology and anatomy".

Further advancement in our understanding about the circle of Willis was made by the detailed microanatomical study initiated by M. G. Yasargil and A. Rothon.

Actually, after a historical journey of more than 500 years we know that the circle of Willis is the most commonplace of aneurysmal formation; it is important for the collateral flow of the brain and for the reduction of the hemodynamic stress of the arteries of the brain; the perforating vessels of the $\mathrm{CW}$ have to be preserved during surgery and some parts of the CW can be sacrificed during surgery if the collateral flow and the perforating vessels are preserved; it can be an important alternative for access during endovascular procedures.

\section{Comment on this article:}

\section{$f(3)$ in $8+$ S. $P$}

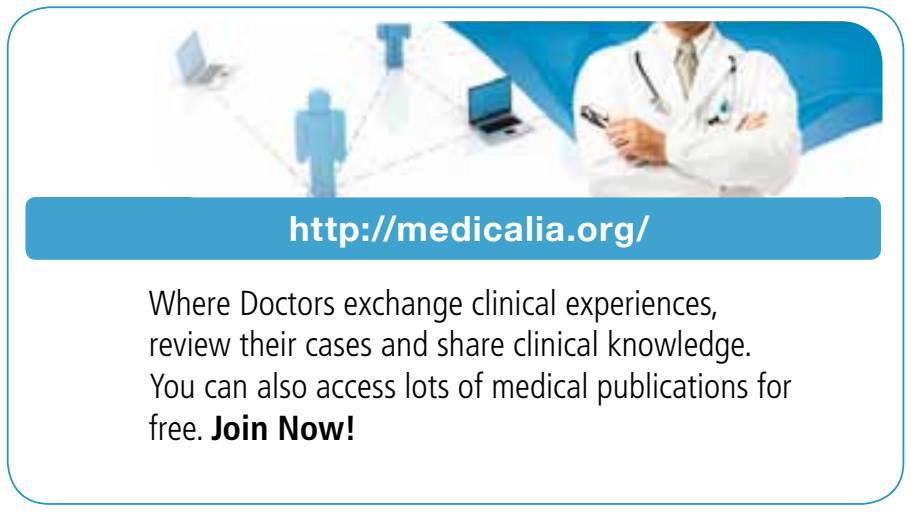

\section{Publish with iMedPub}

\section{http://www.imed.pub}

Neurology and Neuroscience (jneuros.com) is a hybrid, peerreviewed journal that considers articles concerned with any aspect of clinical neurosciences such as neurology, psychiatry and neurosurgery, as well as basic research on neuroscience where neurologists and neuroscientists publish together.

\section{Submit your manuscript here:} http://www.jneuros.com 